Article

\title{
Design, Synthesis and Investigation of the Potential Anti-Inflammatory Activity of 7-O-Amide Hesperetin Derivatives
}

\author{
Yilong Zhang ${ }^{1,2,3,+}$, Yan Zheng ${ }^{1,2,3,+}$, Wen Shi ${ }^{1,2,3}$, Yahui Guo ${ }^{1,2}$, Tao Xu ${ }^{1,2,3}$, Zeng Li 1, 2,3, \\ Cheng Huang 1,2,3,* and Jun $\mathrm{Li}^{1,2,3, *}$ \\ 1 The Key Laboratory of Major Autoimmune Diseases, Anhui Province, Anhui Institute of Innovative Drugs, \\ School of Pharmacy, Anhui Medical University, Hefei 230032, China; zhangyl_ahmu@126.com (Y.Z.); \\ 13170023235@163.com (Y.Z.); shiwenahaq@163.com (W.S.); yahuiguo_1@163.com (Y.G.); \\ xutao@ahmu.edu.cn (T.X.); lizeng@ahmu.edu.cn (Z.L.) \\ 2 The Key laboratory of Anti-Inflammatory Immune Medicines, Ministry of Education, Hefei 230032, China \\ 3 Institute for Liver Diseases of Anhui Medical University, Anhui Medical University, Hefei 230032, China \\ * $\quad$ Correspondence: huangcheng@ahmu.edu.cn (C.H.); lj@ahmu.edu.cn (J.L.); Tel./Fax: +86-551-6516-1001 (J.L.) \\ + These authors contributed equally to this paper.
}

Received: 14 August 2019; Accepted: 1 October 2019; Published: 11 October 2019

\begin{abstract}
To develop new anti-inflammatory agents, a series of 7-O-amide hesperetin derivatives was designed, synthesized and evaluated for anti-inflammatory activity using RAW264.7 cells. All compounds showed inhibitory effect on LPS-induced NO production. Among them, 7-O-(2-(Propylamino)-2-oxoethyl)hesperetin (4d) and 7-O-(2-(Cyclopentylamino)2-oxoethyl)hesperetin (4k) with hydrophobic side chains exhibited the most potent NO inhibitory activity $\left(\mathrm{IC}_{50}=19.32\right.$ and $16.63 \mu \mathrm{M}$, respectively), showing stronger inhibitory effect on the production of pro- inflammatory cytokines tumor necrosis factor (TNF- $\alpha$ ), interleukin- 6 (IL-6) and interleukin- $1 \beta$ (IL-1 $\beta$ ) than indomethacin and celecoxib at $10 \mu \mathrm{M}$. The structure-activity relationships (SARs) suggested that the 7-O-amide unit was buried in a medium-sized hydrophobic cavity of the bound receptor. Furthermore, compound $4 \mathrm{~d}$ could also significantly suppress the expression of inducible nitric oxide synthase enzymes (iNOS) and cyclooxygenase-2 (COX-2), through the nuclear factor-kappa $\mathrm{B}(\mathrm{NF}-\mathrm{kB})$ signaling pathway.
\end{abstract}

Keywords: hesperetin derivatives; synthesis; inflammatory; NF-kB; structure-activity relationships.

\section{Introduction}

Inflammation which is a biological response to harmful stimuli such as pathogens that cause tissue and cell damage is a central feature of many pathological conditions [1,2]. Persistent inflammation can cause severe damage to organisms, which is detrimental to health [3]. Citrus is the fruit of Rutaceae plants that produce oranges (Citrus reticulata Blanco) and its cultivars. Hesperetin and hesperidin are the primary active contents of citrus fruits. Hesperidin is a flavanone glycoside, which is abundantly present in citrus fruits and often consumed in the form of orange juice. Hesperetin, derived from the hydrolysis of hesperidin, is the major flavonoid occurring in sweet oranges and orange juice [4,5]. Previous studies have shown that hesperetin has a variety of pharmacological effects, including anti-inflammatory [6,7], anti-tumor [8], anti-oxidant [9] and neuroprotective properties [10-13]. Although hesperetin has a wide range of pharmacological effects, its poor aqueous solubility, low bioavailability, rapid clearance in vivo, and short plasma circulation time limit its wide application $[14,15]$. Structural modification of bioactive natural products according to molecular characteristics was an essential approach in the search for new lead compounds. 
In our previous studies, we synthesized a series of hesperidin derivatives and screened their anti-inflammatory activities in vitro as well as in vivo [16-19]. An earlier study reported that the elimination half-life $\left(\mathrm{t}_{1 / 2}\right)$ of hesperetin was $1.78 \mathrm{~h}$ in rats [15] and $3.12 \mathrm{~h}$ in healthy human subjects [14]. Pharmacokinetic studies of Mannich base hesperetin derivatives have shown that were rapidly metabolized, primarily to different combinations of 7-O-glucuronides and 7-O-sulfates [19,20]. We have designed and synthesized 7-O-substituent hesperetin derivatives for improving the activity and bioavailability $[16,21,22]$. It was found that the introduction of hydrophobic alkyl and benzyl groups at 7-OH improved their anti-inflammatory activities [22]. However, the introduction of hydrophobic $\alpha, \beta$-unsaturated amides resulted in weak anti-inflammatory activity [16]. We considered that the size and shape of the cavity of bound receptor, which in the 7-OH direction, affected the anti-inflammatory activity of 7-O-substituent hesperetin derivatives. Based on the above observations, we proceeded with modification of 7-O-substituent hesperetin derivatives using following strategies: (a) shortening the length of $\alpha, \beta$-unsaturated acid moiety at 7-OH, namely replacing it with acetic acid (3); (b) converting the carboxyl group to an amide functionality with linear alkyl, branched alkyl, cycloalkyl, heterocycle or hydrophilic groups (Scheme 1). The inhibitory activity on NO, tumor necrosis factor (TNF- $\alpha$ ), interleukin-6 (IL-6) and interleukin-1 $\beta$ (IL-1 $\beta$ ) production in lipopolysaccharide (LPS)-induced mouse macrophage, abelson murine leukemia virus transformed (RAW264.7 cells) and anti-inflammatory mechanism of these derivatives investigated as well.

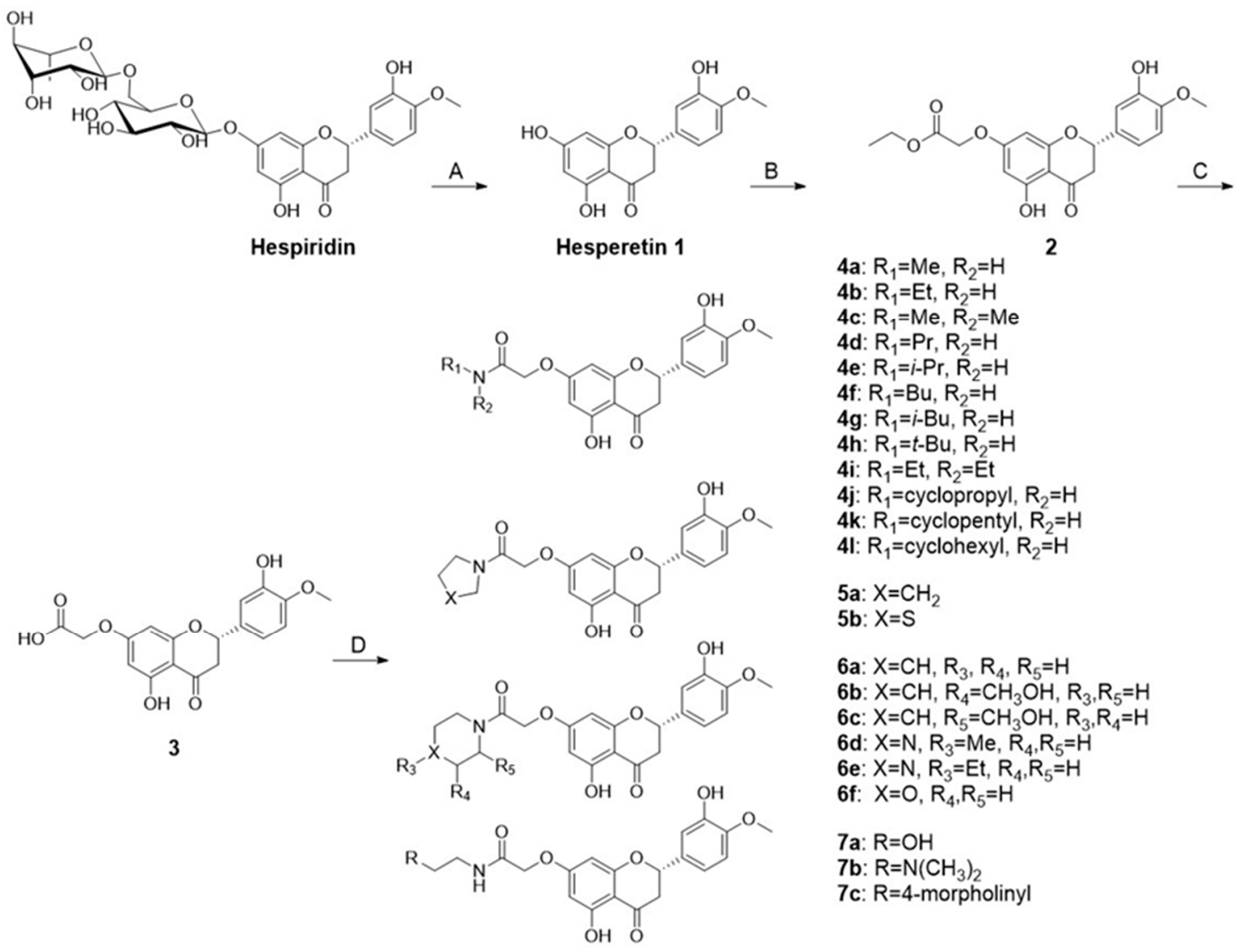

Scheme 1. Synthesis of hesperetin derivatives and conditions: (A) $96 \% \mathrm{H}_{2} \mathrm{SO}_{4}, \mathrm{EtOH}, 80{ }^{\circ} \mathrm{C}$, reflux; (B) DMF, $\mathrm{K}_{2} \mathrm{CO}_{3}$, Ethyl bromoacetate, r.t; (C) $10 \% \mathrm{NaOH}, \mathrm{H}_{2} \mathrm{O}, 0{ }^{\circ} \mathrm{C} ; 10 \% \mathrm{HCl}$, ice bath; (D) EDC.HCl, $\mathrm{HOBT}, \mathrm{CHCl}_{3}$, Amines (4a-1: Linear alkylamine, branched alkylamine and cycloalkylamine; $5 \mathbf{a}-\mathbf{b}$ : Five-membered heterocyclic amine; $\mathbf{6 a}-\mathbf{f}$ : Six-membered heterocyclic amine; $7 \mathbf{a}-\mathbf{c}$ : Amine with terminal hydrophilic group), r.t. 


\section{Results and Discussion}

\subsection{Chemistry}

Since hesperidin was extremely difficult to dissolve in common solvents and was relatively easily isolated from plants' extract, the target compounds $\mathbf{4 a - 4 1}, \mathbf{5 a}-\mathbf{5 b}, \mathbf{6 a}-\mathbf{6 f}$, and $\mathbf{7 a}-\mathbf{7 c}$ were synthesized starting from commercially available hesperidin as illustrated in Scheme 1 . At the very start, hesperetin (1) was obtained by sulfuric acid hydrolysis of hesperidin in ethanol [23] and then the synthesis of the target intermediates was conducted. Compound 2 was prepared by a substitution reaction treating hesperetin with ethyl bromoacetate and $\mathrm{K}_{2} \mathrm{CO}_{3}[16,24]$. As shown in Table 1, ethyl bromoacetate selectively substituted at the 7-OH position. Since compounds 2 and 3 were easily oxidized under $\mathrm{pH}>10$, hydrolysis reaction was carried out at low temperature as soon as possible. In the condensation reactions of amino and carboxyl groups, 1-(3-dimethylaminopropyl)-3-ethylcarbodiimide hydrochloride $(\mathrm{EDC} \cdot \mathrm{HCl})$ and 1-hydroxybenzotriazole $(\mathrm{HOBT})$ are indispensable catalysts [24,25]. ${ }^{1} \mathrm{H}-\mathrm{NMR}$ spectra and chemical shifts of hesperidin are shown in Figure SO of the Supporting Information.

Table 1. ${ }^{1} \mathrm{H}-\mathrm{NMR}$ data of the compounds' $\mathrm{OH}$ groups ( $\delta$ in $\left.\mathrm{ppm}\right)$.

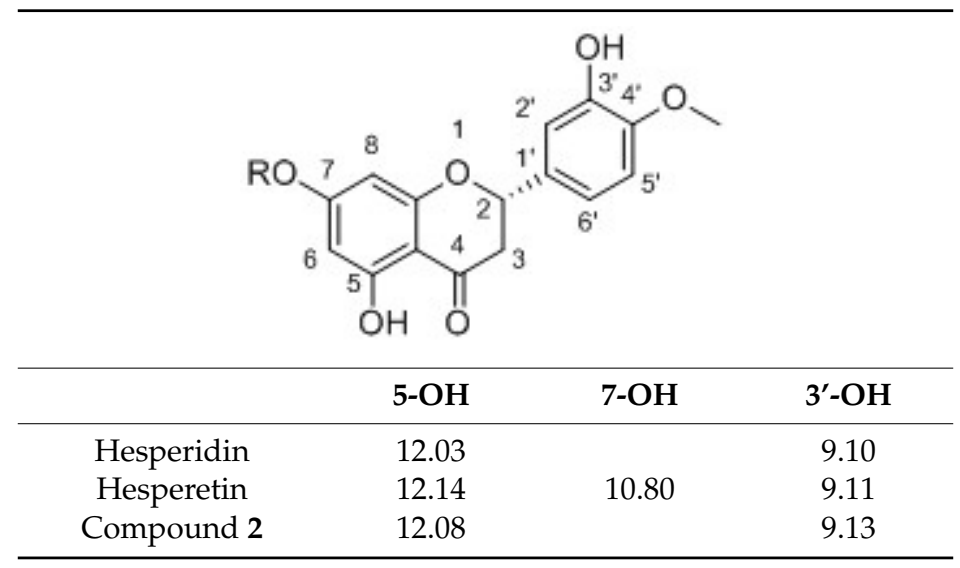

\subsection{Evaluation of Biological Activities}

\subsubsection{Cytotoxicity of Hesperetin Derivatives}

Compounds $\mathbf{4 a - 4 1 , 5 a - 5 b , 6 a - 6 f , 7 a - 7 c ~ w e r e ~ a s s e s s e d ~ f o r ~ t o x i c i t y ~ a g a i n s t ~ R A W 2 6 4 . 7 ~ c e l l ~ l i n e s ~ u s i n g ~}$ the 3-(4,5-dimethylthiazol-2-yl)-2,5-diphenyltetrazolium bromide (MTT) assay [26]. The cytotoxicity tests were performed at the concentration of $40 \mu \mathrm{M}$ and the results are shown in Table 2. After $40 \mu \mathrm{M}$ treatment, the cell viability of all of the hesperetin derivatives was more than $90 \%$. It was thus shown that the anti-inflammatory activities of hesperetin derivatives were not due to their cytotoxicity. In subsequent anti-inflammation studies, the highest concentration of hesperetin derivatives was set below $40 \mu \mathrm{M}$. The viability assay of RAW264.7 cells treated with different concentrations of compound $\mathbf{4 d}$ are shown in Figure 1. There was no significant cytotoxicity of compound $\mathbf{4 d}$ at concentrations up to $100 \mu \mathrm{M}$. 
Table 2. Cell viability of RAW 264.7 cells at a compound concentration of $40 \mu \mathrm{M}$.

\begin{tabular}{|c|c|}
\hline Compound & $\%$ Cell Viability in $40 \mu \mathrm{M}$ \\
\hline DMSO & $0.86 \pm 0.07^{\mathrm{ns}}$ \\
\hline DMSO + LPS & 1.00 \\
\hline $4 a$ & $0.8 \pm 0.01^{\mathrm{ns}}$ \\
\hline $4 b$ & $0.93 \pm 0.02^{\mathrm{ns}}$ \\
\hline $4 c$ & $0.89 \pm 0.04^{\mathrm{ns}}$ \\
\hline $4 d$ & $0.91 \pm 0.04^{\mathrm{ns}}$ \\
\hline $4 e$ & $1 \pm 0.08^{\mathrm{ns}}$ \\
\hline $4 f$ & $0.93 \pm 0.01^{\mathrm{ns}}$ \\
\hline $4 \mathrm{~g}$ & $0.93 \pm 0.01^{\mathrm{ns}}$ \\
\hline $4 \mathrm{~h}$ & $1 \pm 0.03^{\mathrm{ns}}$ \\
\hline $4 i$ & $0.87 \pm 0.01^{\mathrm{ns}}$ \\
\hline $4 j$ & $0.88 \pm 0.03^{\mathrm{ns}}$ \\
\hline $4 \mathrm{k}$ & $0.96 \pm 0.14^{\mathrm{ns}}$ \\
\hline 41 & $1.07 \pm 0.01^{\mathrm{ns}}$ \\
\hline $5 a$ & $0.77 \pm 0.01^{\mathrm{ns}}$ \\
\hline $5 b$ & $0.88 \pm 0.03^{n s}$ \\
\hline $6 a$ & $1.03 \pm 0.02^{\mathrm{ns}}$ \\
\hline $6 b$ & $1.01 \pm 0.11^{\mathrm{ns}}$ \\
\hline $6 c$ & $0.97 \pm 0.36^{\mathrm{ns}}$ \\
\hline $6 d$ & $0.98 \pm 0.01^{\mathrm{ns}}$ \\
\hline $6 e$ & $1.08 \pm 0.11^{\mathrm{ns}}$ \\
\hline $6 f$ & $1.17 \pm 0.09 \mathrm{~ns}$ \\
\hline $7 a$ & $1 \pm 0.03^{\mathrm{ns}}$ \\
\hline $7 \mathrm{~b}$ & $1.07 \pm 0.09^{\mathrm{ns}}$ \\
\hline $7 \mathrm{c}$ & $0.85 \pm 0.02^{\mathrm{ns}}$ \\
\hline
\end{tabular}

Cell viabilities of hesperetin derivatives on RAW264.7 cells. Data presented as mean $\pm \operatorname{SD}(n=3)$. The difference was considered without statistically significance (ns) compared with DMSO + LPS group.

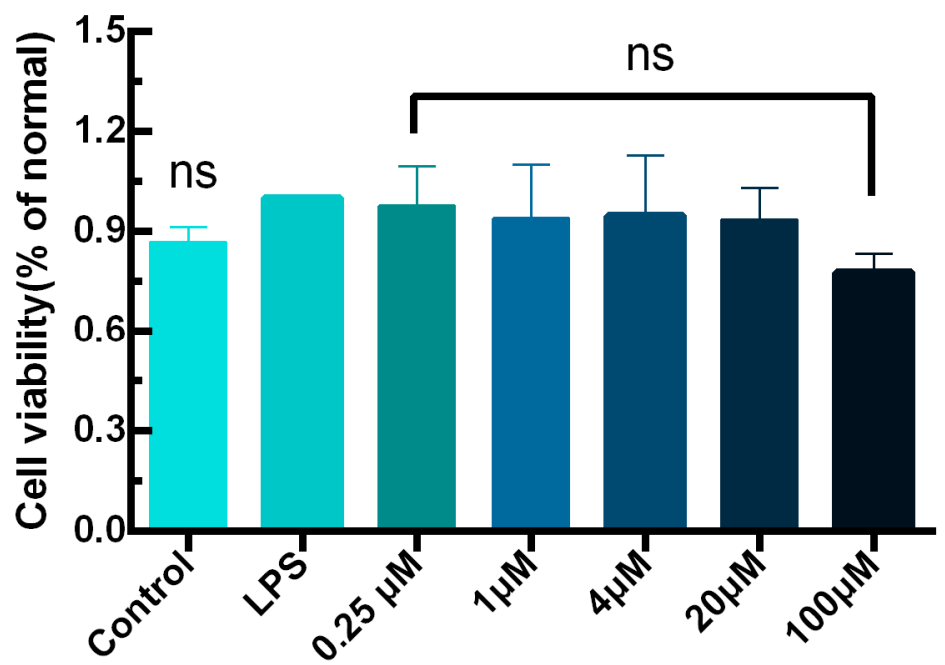

Figure 1. The viability assay of RAW264.7 cells was determined by MTT assay on different concentrations of compound $4 \mathrm{~d}$. Compared with the LPS group and the control group. The results are presented as the means \pm SD of three different experiments. The difference was considered without statistically significance (ns).

\subsubsection{Inhibitory Activity on LPS-Induced NO Production}

$\mathrm{NO}$ is an important inflammatory mediator and is overproduced and secreted out of mouse macrophages in response to bacterial lipopolysaccharide [27]. To evaluate the anti-inflammatory activity of hesperetin derivatives, the secretion level of $\mathrm{NO}$ was detected in the medium of RAW264.7 cells after LPS stimulated with Griess reagent. Before the cells were treated with LPS $(1 \mu \mathrm{g} / \mathrm{mL})$ for 
$24 \mathrm{~h}$, pretreatment with the compounds for 1 hour. Later, the expression level of NO production was markedly reduced. The inhibitory activity of the compounds as summarized in Table 3. All hesperetin derivatives could decrease the release of NO induced by LPS. Among them, compounds $4 \mathbf{d}, \mathbf{4 e}, \mathbf{4 g}, \mathbf{4 k}$, and 6a significantly alleviated the increase of LPS-induced NO release. As expected, compounds with hydrophobic side chains exhibited better NO inhibitory activity than with hydrophilic side chains, such as $4 \mathbf{d}>\mathbf{7 a} ; \mathbf{4} \mathbf{g}>\mathbf{7 b} ; \mathbf{6} \mathbf{a}>\mathbf{6 b}, \mathbf{6} \mathbf{c}$. While extended the length of the amide side chain and the inhibitory activities increased $(4 d>4 c>4 a ; 4 e>4 b)$. These showed the side chains of 7-O-amide buried in a hydrophobic cavity. On the other hand, the cavity was medium-sized, large enough to accommodate cyclopentyl and propyl groups, but not enough to accommodate cyclohexyl and butyl ones $(\mathbf{4 a}<\mathbf{4 b}<$ 4d $>$ 4f; 4k > 41). Overall, 7-O-amide hesperetin derivatives displayed preferably anti-inflammatory activity, particularly, compounds $4 \mathbf{d}$ and $4 \mathbf{k}$ exhibited the best inhibitory effect. At the same time, compound $4 \mathbf{d}$ inhibited the production of $\mathrm{NO}$ in $38.17 \%$ at the concentration of $10 \mu \mathrm{M}$ and the $\mathrm{IC}_{50}$ value of compound $\mathbf{4 d}$ on $\mathrm{NO}$ inhibition was $19.32 \mu \mathrm{M}$ while indomethacin and celecoxib showed values of $35.30 \mu \mathrm{M}$ and $26.35 \mu \mathrm{M}$. These results showed that compound $4 \mathbf{d}$ exerted the suppression of $\mathrm{NO}$ activity in a dose-dependent manner.

Table 3. $\mathrm{IC}_{50}$ and Inhibition rate on NO production in LPS-treated RAW264.7 cells at the compound concentration of $10 \mu \mathrm{M}$.

\begin{tabular}{|c|c|c|}
\hline Compound & NO Inhibition in $10 \mu \mathrm{M}(\%)$ & $\mathrm{IC}_{50}(\mu \mathrm{M})$ \\
\hline Ind & $12.87 \pm 3.09 * * *$ & $35.30 \pm 8.07$ \\
\hline Cel & $14.48 \pm 3.61^{* * * *}$ & $26.35 \pm 0.46$ \\
\hline $4 a$ & $16.00 \pm 0.06^{* * * *}$ & $38.53 \pm 2.00$ \\
\hline $4 b$ & $21.49 \pm 1.29^{* * * *}$ & $29.94 \pm 3.40$ \\
\hline $4 c$ & $13.52 \pm 1.63^{* * * *}$ & $32.46 \pm 2.46$ \\
\hline $4 d$ & $38.17 \pm 1.13^{* * * *}$ & $19.32 \pm 0.47$ \\
\hline $4 e$ & $27.15 \pm 5.88^{* * * *}$ & $26.13 \pm 1.21$ \\
\hline $4 f$ & $17.99 \pm 0.82 * * * *$ & $29.71 \pm 3.06$ \\
\hline $4 \mathrm{~g}$ & $23.51 \pm 0.74^{* * * *}$ & $24.59 \pm 0.22$ \\
\hline $4 \mathrm{~h}$ & $17.49 \pm 1.33^{* * * *}$ & $42.02 \pm 6.15$ \\
\hline $4 \mathbf{i}$ & $17.48 \pm 2.33^{* * * *}$ & $30.48 \pm 1.66$ \\
\hline $4 j$ & $9.57 \pm 5.53 *$ & $41.70 \pm 2.79$ \\
\hline $4 \mathrm{k}$ & $40.85 \pm 0.64^{* * * *}$ & $16.63 \pm 0.85$ \\
\hline 41 & $20.34 \pm 2.00^{* * * *}$ & $33.30 \pm 3.30$ \\
\hline $5 a$ & $18.92 \pm 4.02 * * * *$ & $36.22 \pm 5.83$ \\
\hline $5 b$ & $22.74 \pm 5.71^{* * * *}$ & $30.03 \pm 0.43$ \\
\hline $6 a$ & $30.20 \pm 4.67^{* * * *}$ & $23.40 \pm 1.64$ \\
\hline $6 b$ & $19.33 \pm 1.94^{* * * *}$ & $31.12 \pm 2.93$ \\
\hline $6 c$ & $9.10 \pm 3.67 *$ & $40.55 \pm 5.56$ \\
\hline $6 d$ & $22.20 \pm 6.24^{* * * *}$ & $33.82 \pm 5.56$ \\
\hline $6 e$ & $22.95 \pm 2.74^{* * * *}$ & $32.28 \pm 3.57$ \\
\hline $6 f$ & $20.96 \pm 0.31^{* * * *}$ & $32.62 \pm 1.514$ \\
\hline $7 a$ & $15.03 \pm 1.99^{* * * *}$ & $28.43 \pm 5.33$ \\
\hline $7 \mathrm{~b}$ & $12.37 \pm 0.67^{* * *}$ & $92.51 \pm 33.74$ \\
\hline $7 \mathrm{c}$ & $18.38 \pm 4.55^{* * * *}$ & $42.38 \pm 2.06$ \\
\hline
\end{tabular}

After pretreatment with the compounds for $1 \mathrm{~h}$, RAW264.7 cells were stimulated by LPS. Data presented as mean \pm $\mathrm{SD}(\mathrm{n}=3)$. The difference was considered statistically significant when $\left.p^{*}\right)<0.05, p\left({ }^{* * *}\right)<0.001, p\left({ }^{* * * *}\right)<0.0001$.

\subsubsection{Inhibitory Activity on TNF- $\alpha$, IL-6 and IL-1 $\beta$ Production in LPS-Induced RAW264.7 Cells}

When inflammation occurs, LPS-activated macrophages produce a variety of inflammatory cytokines, including TNF- $\alpha$, interleukins (ILs), and nitric oxide (NO) [28], which show a host shielding effect and also accelerate the occurrence of the inflammatory response during inflammatory situations. To evaluate the anti-inflammatory activity of hesperetin derivatives, the levels of TNF- $\alpha$, IL- 6 and IL- $1 \beta$ in the medium of LPS-induced macrophage cells were detected by enzyme linked immunosorbent assay (ELISA). As shown in Figure $2 \mathrm{~A}-\mathrm{C}$, the expression levels of TNF- $\alpha$, IL-6 and IL- $1 \beta$ were 
significantly increased after treatment with LPS, compared to the Control group, and were significantly down-regulated by most of the hesperetin derivatives at the concentration of $10 \mu \mathrm{M}$, which was consistent with our observations of its activity in $\mathrm{NO}$ inhibition. Compound $4 \mathbf{d}, \mathbf{4 e}$, and $4 \mathbf{k}$ had greater inhibitory effects than indomethacin (Ind) and celecoxib (Cel). Compound $4 \mathbf{d}$ inhibited the LPS-induced production of IL-6, IL-1 $\beta$ and TNF- $\alpha$ in a dose-dependent manner (Figure 2D-F). Later, we will select one of them as lead compound and modify the structure at the $3^{\prime}-\mathrm{OH}, 5-\mathrm{OH}$ and 4-carbonyl positions. Lipinski's drug-likeness Rule of five (Ro5) suggests molecular weight (MW) $<500$ [29]. Compounds 4d (MW = 401) and 4k (MW = 427) have similar structures and should have the same mechanism. Therefore, compound $4 \mathbf{d}$ with lower molecular weight was selected to further explore the mechanism(s) of the anti-inflammatory effect.

A

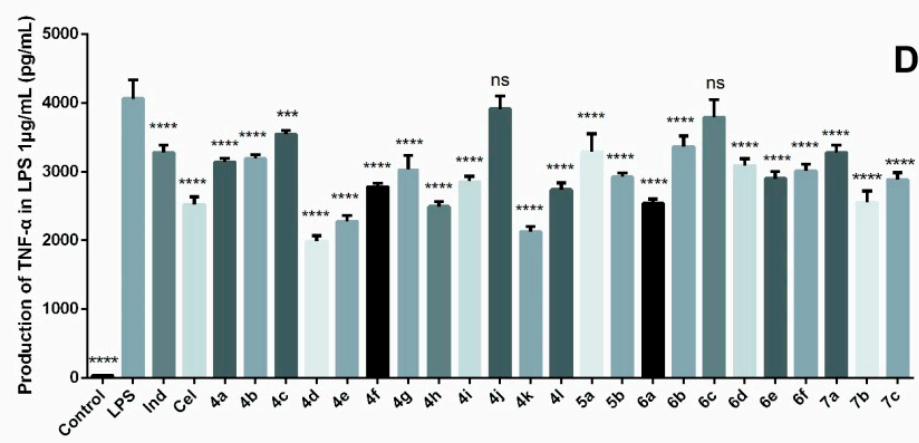

B

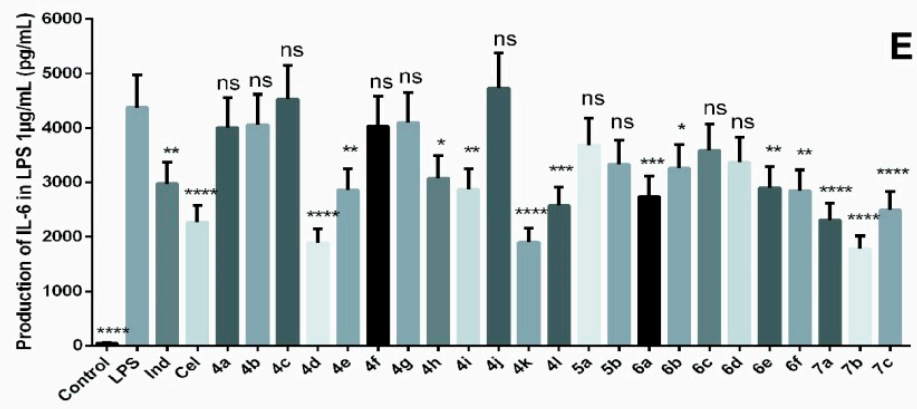

C

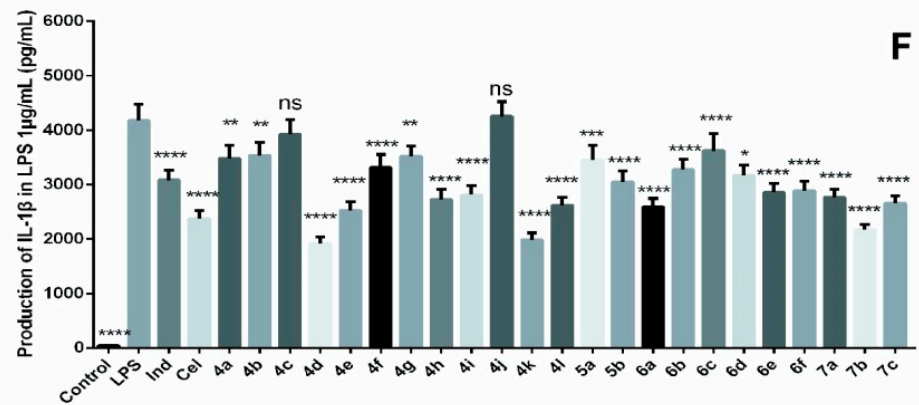

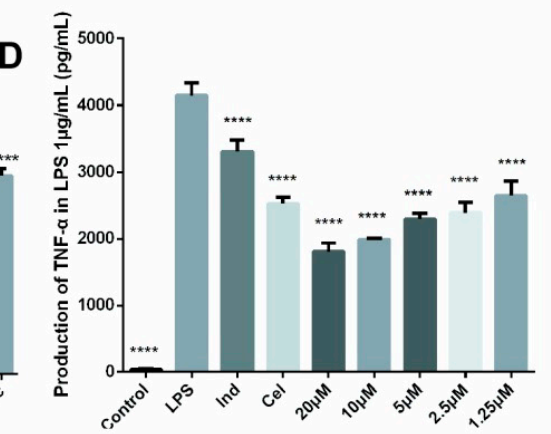

E
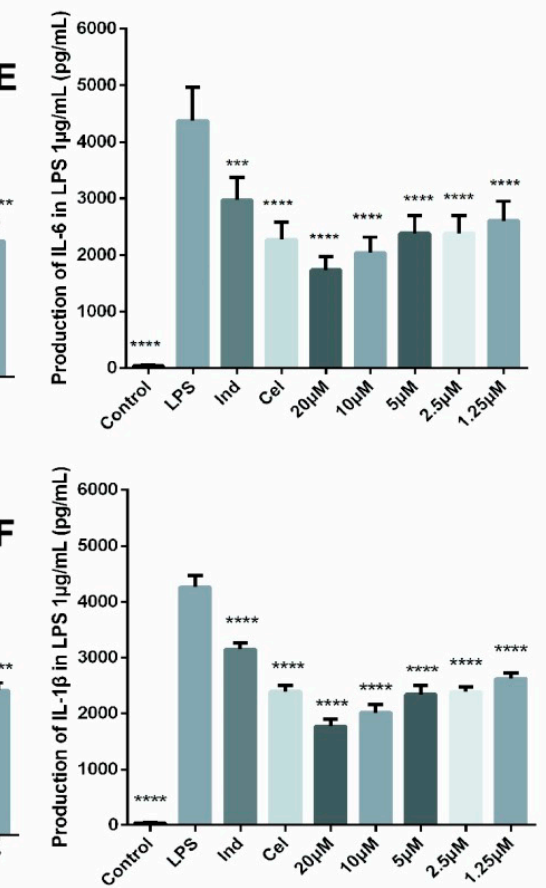

Figure 2. Initial evaluation releases of TNF- $\alpha$, IL- 6 and IL-1 $\beta$ in RAW264.7 cells. TNF- $\alpha$, IL- 6 and IL-1 $\beta$ in the culture medium were measured by ELISA. (A-C) Cells were treated with $10 \mu \mathrm{M}$ compounds. (D-F) Cells were pretreated with different concentrations of compound $4 \mathbf{d}$. The levels of TNF- $\alpha$, IL-6 and IL-1 $\beta$ in the medium were determined with the ELISA kit. Indomethacin (Ind) and celecoxib (Cel) were used as a positive control drug. The results were presented as the means \pm SD of three different experiments. The difference was considered statistically significant when $p\left({ }^{*}\right)<0.05, p\left({ }^{* *}\right)<0.01$, $\left.p\left(^{* * *}\right)<0.001, p{ }^{* * * *}\right)<0.0001$ compared with LPS-stimulated group. 
2.2.4. Inhibitory Activity on Expression Levels of COX-2 and iNOS in LPS-Induced RAW264.7 Cells by Compound 4d

In the process of inflammation, inducible nitric oxide synthase enzymes (iNOS) are induced to overexpression in inflammatory cells when exposed to pro-inflammatory cytokines, which further leads to excessive production of NO. The inhibition of NO production by compound $4 \mathbf{d}$ may be correlated with its suppressive effect on LPS-induced iNOS. Thus, the inhibitory effects of compound $\mathbf{4} \mathbf{d}$ on LPS-mediated expressions of iNOS were analyzed by western blotting [30,31]. Nitric oxide synthase (iNOS) protein levels were analyzed after exposure to LPS for $24 \mathrm{~h}$ in the presence or absence of compound $4 \mathrm{~d}(5,10,20 \mu \mathrm{M})$. As expected, LPS stimulation could markedly increase iNOS protein expression, and compound $4 \mathbf{d}$ significantly decreased the expression level of iNOS induced by LPS in a dose-dependent manner (Figure 3). Cyclooxygenase-2 (COX-2) is an important indicator of anti-inflammatory inhibitors, maintaining a low level in normal tissues. COX-2 is rapidly up-regulated when inflammation occurs, and the downstream inflammatory mediators such as prostaglandin secretion rise rapidly, further aggravating the development of inflammation. We also found that compound $\mathbf{4 d}$ was capable of reducing the expression level of COX-2 in a concentration-dependent way (Figure 3). Bay 11-7082 (5 $\mu \mathrm{M})$ used as a positive control.

\section{COX-2}

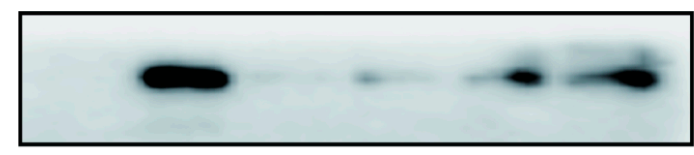

iNOS

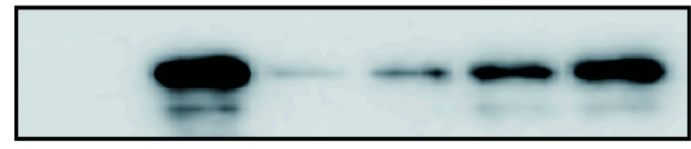

$\beta$-actin
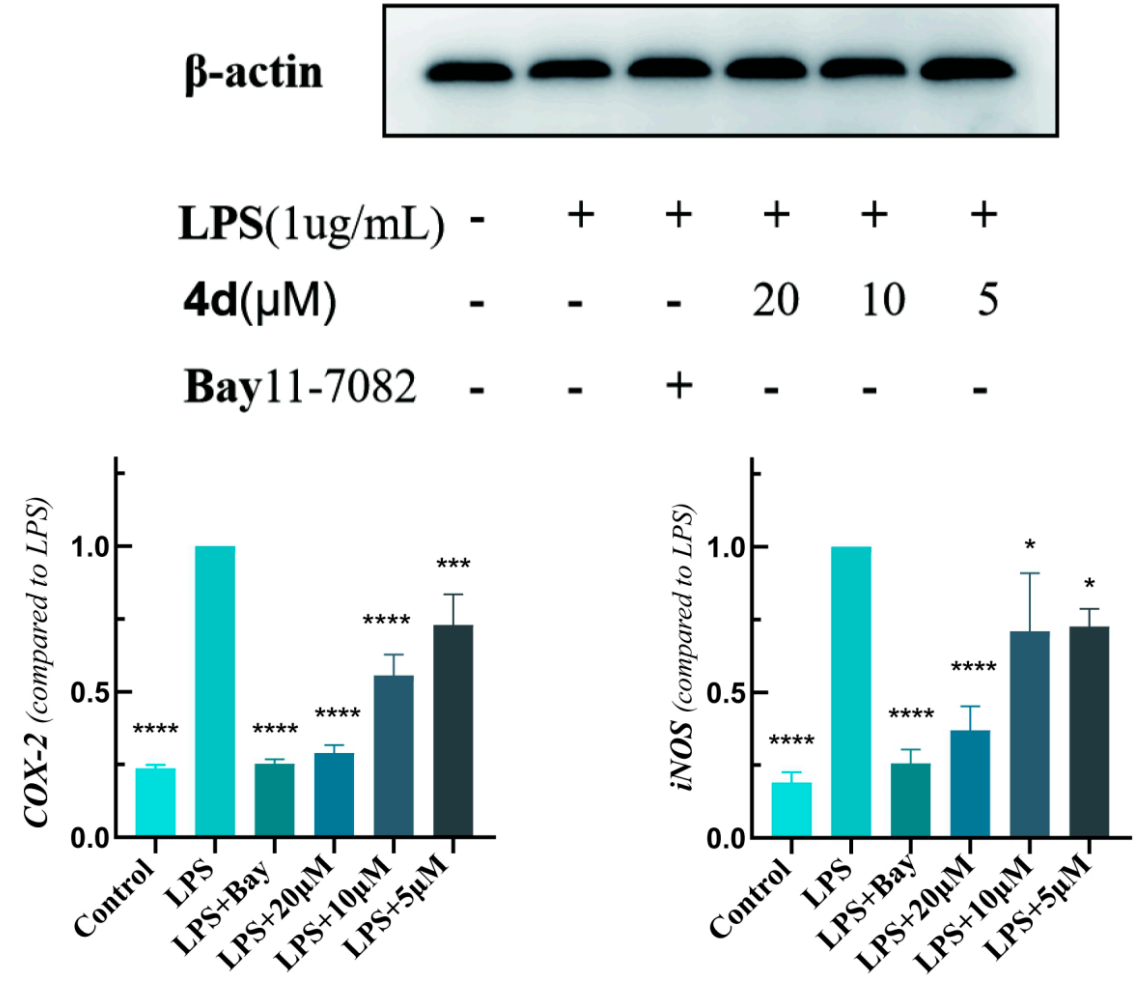

Figure 3. Compound 4d inhibited expression levels of COX-2 and iNOS in LPS-induced RAW264.7 cells. The results were presented as the means $\pm \mathrm{SD}$ of three different experiments. The difference was considered statistically significant when $p\left({ }^{*}\right)<0.05, p\left({ }^{* * *}\right)<0.001, p\left({ }^{* * *}\right)<0.0001$. 
2.2.5. Negative Regulation of NF-кB Signal Pathway in LPS-Induced RAW264.7 Cells by Compound 4d

Stimulation with LPS leads to the activation of nuclear factor-kappa B (NF-kB), which is a well-known transcription factor that positively regulates inflammation. When NF- $\mathrm{kB}$ activation is stimulated by LPS, inhibitor of NF- $\kappa B$ (I $\kappa$ B) protein phosphorylated and degraded frees NF- $\kappa$ B p65 subunit from sequestration, allowing it to translocate to the nucleus, bind to target promoters, and turn on the transcriptions of inflammation genes including TNF- $\alpha$ and IL-6. Therefore, Western blotting was used to examine the effects of compound $4 \mathrm{~d}$ on LPS induced transcriptional activity of NF- $\mathrm{KB}$ in RAW264.7 cells.

As shown in Figure 4, compound $\mathbf{4 d}$ markedly decreased the phosphorylation of $\operatorname{I} \mathrm{B} \alpha$. The protein expressions of NF- $\mathrm{KB}$ and I $\mathrm{KB} \alpha$ were also down-regulated, compared with the LPS induced group. At the same time, LPS increased NF- $\mathrm{kB}$ p65 nuclear translocation, whereas pretreatment with compound $4 \mathrm{~d}(5,10,20 \mu \mathrm{M})$ concentration-dependently reversed LPS-induced NF- $\mathrm{KB}$ p65 nuclear translocation, suggesting that compound $4 \mathrm{~d}$ inhibited NF- $\mathrm{kB}$ activation. These results further confirmed the anti-inflammatory effect of $\mathbf{4 d}$, at least in part, through modulation of NF- $\mathrm{kB}$ activation.

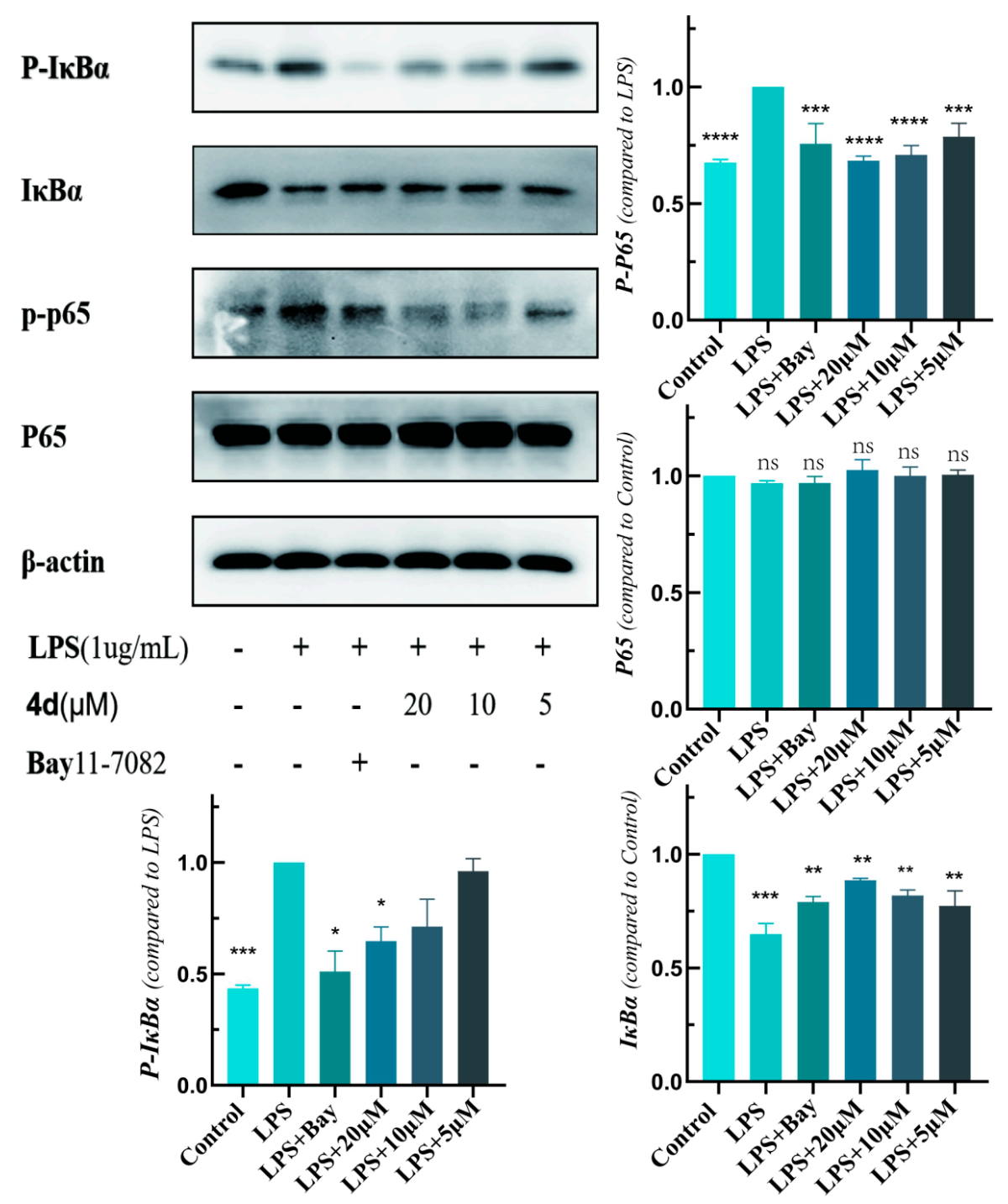

Figure 4. Compound 4d negatively regulated NF- $\mathrm{BB}$ signal pathway in LPS-induced RAW264.7 cells. The results were presented as the means \pm SD of three different experiments. The difference was considered statistically significant when $p\left({ }^{*}\right)<0.05, p\left({ }^{* * *}\right)<0.001, p\left({ }^{* * * *}\right)<0.0001$ or no significance (ns) compared with LPS-stimulated group. 


\section{Materials and Methods}

\subsection{Chemistry}

\subsubsection{General Information}

All reagents were purchased from commercial sources and were used without further purification. Melting points were determined on an $S G W^{\circledR}$ X-4A apparatus (Shanghai Instrument Physical Optics Instrument Co., Ltd., Shanghai, China). ${ }^{1} \mathrm{H}-\mathrm{NMR}$ and ${ }^{13} \mathrm{C}-\mathrm{NMR}$ spectra were recorded on an AV-400 MHz instrument (Bruker, Fallanden, Switzerland) in dimethyl sulfoxide (DMSO- $\left.d_{6}\right)$. Chemical shifts are reported in parts per million $(\delta)$ downfield from the signal of tetramethylsilane (TMS) as internal standards. Coupling constants are reported in Hz. The multiplicity is defined by s (singlet), $\mathrm{d}$ (doublet), $\mathrm{t}$ (triplet), br (broad) or $\mathrm{m}$ (multiplet). High resolution mass spectra (HRMS) were obtained on a 1260-6221 TOF mass spectrometry system (Agilent, Santa Clara, CA, USA). Column and thin-layer chromatography (CC and TLC, resp.) were performed on silica gel (200-300 mesh) and silica gel GF254 (Qingdao Marine Chemical Factory, Qingdao, China), respectively.

\subsubsection{Synthetic Methods for All Compounds}

Synthesis of Hesperetin (1)

To a solution of ethanol $(640 \mathrm{~mL})$ and $98 \% \mathrm{H}_{2} \mathrm{SO}_{4}(80 \mathrm{~mL})$ was added hesperidin $(72 \mathrm{~g}, 0.12 \mathrm{~mol})$, the suspension was heated at $80{ }^{\circ} \mathrm{C}$ for $8 \mathrm{~h}$. The reaction mixture was allowed to cool to room temperature, then poured into ice water $(2 \mathrm{~L})$. The precipitate was filtered, washed with water and dried. The mixture was dissolved in ethanol and heated to reflux for $1 \mathrm{~h}$, heating was stopped and activated charcoal was added to the solution for $15 \mathrm{~min}$. The solution was filtered and washed with hot ethanol. The ethanol solution was concentrated under the reduced pressure, and the residue was recrystallized from ethanol and $\mathrm{CH}_{2} \mathrm{Cl}_{2}$ to obtain hesperetin (1) [23] as a white powder (31.5 g, yield 87\%), m.p. $229.5-231.6{ }^{\circ} \mathrm{C} ;{ }^{1} \mathrm{H}-\mathrm{NMR}: \delta 12.14$ (s, 1H, 5-OH), 10.80 (s, 1H, 7-OH), 9.11 (s, 1H, 3'-OH), 6.95-6.92 (m, J = 5.1, 3.2 Hz, 2H, 2'-H, 5'-H), $6.87\left(\mathrm{dd}, J=8.3,2.0 \mathrm{~Hz}, 1 \mathrm{H}, 6^{\prime}-\mathrm{H}\right), 5.89$ (d, J = 2.1 Hz, $1 \mathrm{H}, 8-\mathrm{H}), 5.88(\mathrm{~d}, J=2.1 \mathrm{~Hz}, 1 \mathrm{H}, 6-\mathrm{H}), 5.43(\mathrm{dd}, J=12.4,3.0 \mathrm{~Hz}, 1 \mathrm{H}, 2-\mathrm{H}), 3.77\left(\mathrm{~s}, 3 \mathrm{H}, \mathrm{OCH}_{3}\right), 3.20$ $(\mathrm{dd}, J=17.1,12.4 \mathrm{~Hz}, 1 \mathrm{H}, 3-\mathrm{H}), 2.70(\mathrm{dd}, J=17.1,3.1 \mathrm{~Hz}, 1 \mathrm{H}, 3-\mathrm{H}) .{ }^{13} \mathrm{C}-\mathrm{NMR}: \delta 196.61,167.22,163.92$, 163.24, 148.34, 146.85, 131.54, 118.20, 114.45, 112.34, 102.21, 96.31, 95.49, 78.68, 56.07, 42.46. HRMS (ESI): Calcd. $\mathrm{C}_{16} \mathrm{H}_{14} \mathrm{O}_{6},[\mathrm{M}+\mathrm{H}]^{+} m / z: 303.0875$, found: 303.0881 .

Synthesis of 7-O-(2-ethoxy-2-oxoethyl)hesperetin (2)

To a solution of hesperetin $1(30.2 \mathrm{~g}, 100 \mathrm{mmol})$ and $\mathrm{KHCO}_{3}(30 \mathrm{~g}, 300 \mathrm{mmol})$ in DMF $(400 \mathrm{~mL})$ was added $\mathrm{K}_{2} \mathrm{CO}_{3}(12.4 \mathrm{~g}, 150 \mathrm{mmol})$ stirring at room temperature $\left(25^{\circ} \mathrm{C}\right)$ for $30 \mathrm{~min}$, then bromoacetate $(41.8 \mathrm{~g}, 250 \mathrm{mmol})$ was added to the reaction solution with vigorous stirring for $1 \mathrm{~h}$. The reaction was monitored by TLC. The reaction mixture was acidified with dilute $\mathrm{HCl}$ to $\mathrm{pH} 5-6$ and extracted with EtOAc. The organic phase was washed with brine solution for five times, then dried over anhydrous $\mathrm{Na}_{2} \mathrm{SO}_{4}$, filtered, and concentrated under the reduced pressure. The residue was recrystallized from ethanol and $\mathrm{CH}_{2} \mathrm{Cl}_{2}$ to obtain a white crude product. The crude product was recrystallized from $\mathrm{CH}_{2} \mathrm{Cl}_{2}$ and ether to obtain 7-O-(2-ethoxy-2-oxoethyl)hesperetin (2) [24] (white crystalline powder, $19.8 \mathrm{~g}$, yield $50 \%$ for this reaction step, Scheme 1), m.p. $127.8-130.2{ }^{\circ} \mathrm{C} ;{ }^{1} \mathrm{H}-\mathrm{NMR}: \delta 12.08(\mathrm{~s}, 1 \mathrm{H}, 5-\mathrm{OH})$, $9.13\left(\mathrm{~s}, 1 \mathrm{H}, 3^{\prime}-\mathrm{OH}\right), 6.98-6.91\left(\mathrm{~m}, 2 \mathrm{H}, 2^{\prime}-\mathrm{H}, 5^{\prime}-\mathrm{H}\right), 6.89\left(\mathrm{dd}, J=8.4,1.5 \mathrm{~Hz}, 1 \mathrm{H}, 6^{\prime}-\mathrm{H}\right), 6.11(\mathrm{~d}, J=2.1 \mathrm{~Hz}$, $1 \mathrm{H}, 8-\mathrm{H}), 6.09(\mathrm{~d}, J=2.1 \mathrm{~Hz}, 1 \mathrm{H}, 6-\mathrm{H}), 5.49(\mathrm{dd}, J=12.5,2.7 \mathrm{~Hz}, 1 \mathrm{H}, 2-\mathrm{H}), 4.87\left(\mathrm{~s}, 2 \mathrm{H}, \mathrm{ArOCH}_{2} \mathrm{C}=\mathrm{O}\right)$, $4.17\left(\mathrm{q}, J=7.1 \mathrm{~Hz}, 2 \mathrm{H}, \mathrm{CCH}_{2} \mathrm{OC}=\mathrm{O}\right), 3.78\left(\mathrm{~s}, 3 \mathrm{H}, \mathrm{OCH}_{3}\right), 3.28(\mathrm{dd}, J=17.1,12.6 \mathrm{~Hz}, 1 \mathrm{H}, 3-\mathrm{H}), 2.75$ $(\mathrm{dd}, J=17.1,2.9 \mathrm{~Hz}, 1 \mathrm{H}, 3-\mathrm{H}), 1.21\left(\mathrm{t}, J=7.1 \mathrm{~Hz}, 3 \mathrm{H}, \mathrm{CH}_{3} \mathrm{COC}=\mathrm{O}\right) .{ }^{13} \mathrm{C}-\mathrm{NMR}: \delta 197.43,168.50,166.08$, 163.54, 163.18, 148.43, 146.94, 131.35, 118.24, 114.59, 112.37, 103.46, 95.65, 94.74, 78.98, 65.22, 61.32, 56.10, 42.60, 14.48. HRMS (ESI): Calcd. $\mathrm{C}_{20} \mathrm{H}_{20} \mathrm{O}_{8},[\mathrm{M}+\mathrm{H}]^{+} \mathrm{m} / z: 389.1252$, found: 389.1257 . 
Synthesis of 7-O-(carboxymethyl)hesperetin (3)

Substituted derivative $2(19.4 \mathrm{~g}, 50 \mathrm{mmol})$ was mixed with $10 \%$ ethanol aqueous solution $(100 \mathrm{~mL})$ under ice-cooling for $30 \mathrm{~min}$. Cooled $10 \% \mathrm{NaOH}(100 \mathrm{~mL})$ was dropped to the reaction solution over $30 \mathrm{~min}$ at $0{ }^{\circ} \mathrm{C}$, and the mixture was stirred for $30 \mathrm{~min}$ at the same temperature. The reaction mixture was acidified with dilute $\mathrm{HCl}$ (ice bath) to $\mathrm{pH} 3-4$. The precipitate was filtered and washed with acidified water, The solid dried in vacuum to obtain the intermediate 3 as a yellow solid $(16.5 \mathrm{~g}, 92 \%$ Scheme 1), m.p. $198.3-202.4^{\circ} \mathrm{C} ;{ }^{1} \mathrm{H}-\mathrm{NMR}: \delta 12.07$ (s, 1H, 5-OH), 9.21 (s, 1H, 3'-OH), 6.97-6.92 (m, 2H, $\left.2^{\prime}-\mathrm{H}, 5^{\prime}-\mathrm{H}\right), 6.89\left(\mathrm{dd}, J=8.4,1.8 \mathrm{~Hz}, 1 \mathrm{H}, 6^{\prime}-\mathrm{H}\right), 6.07(\mathrm{~d}, J=2.2 \mathrm{~Hz}, 1 \mathrm{H}, 8-\mathrm{H}), 6.06(\mathrm{~d}, J=2.2 \mathrm{~Hz}, 1 \mathrm{H}, 6-\mathrm{H})$, $5.48(\mathrm{dd}, J=12.5,2.9 \mathrm{~Hz}, 1 \mathrm{H}, 2-\mathrm{H}), 4.76\left(\mathrm{~s}, 2 \mathrm{H}, \mathrm{ArOCH}_{2} \mathrm{C}=\mathrm{O}\right), 3.77\left(\mathrm{~s}, 3 \mathrm{H}, \mathrm{OCH}_{3}\right), 3.26(\mathrm{dd}, J=17.1$, $12.5 \mathrm{~Hz}, 1 \mathrm{H}, 3-\mathrm{H}), 2.75$ (dd, $J=17.1,3.0 \mathrm{~Hz}, 1 \mathrm{H}, 3-\mathrm{H}) .{ }^{13} \mathrm{C}-\mathrm{NMR}: \delta 197.33,169.97,166.25,163.49,163.11$, 148.41, 146.86, 131.30, 118.29, 114.49, 112.34, 103.34, 95.59, 94.69, 78.93, 65.11, 56.08, 42.53. HRMS (ESI): Calcd. $\mathrm{C}_{18} \mathrm{H}_{16} \mathrm{O}_{8},[\mathrm{M}+\mathrm{H}]^{+} m / z: 361.0919$, found: 361.0933 .

\subsubsection{General Procedure for the Synthesis of Compounds $4 \mathbf{a}-\mathbf{1}, \mathbf{5 a}-\mathbf{b}, \mathbf{6 a}-\mathbf{g}, \mathbf{7 a - c}$}

To a solution of 7-O-(carboxymethyl)hesperetin $\left(3,720 \mathrm{mg}, 2 \mathrm{mmol}\right.$ ) in anhydrous $\mathrm{CHCl}_{3}$ without alcohol $(40 \mathrm{~mL})$ was added HOBt $(811 \mathrm{mg}, 6 \mathrm{mmol}), \mathrm{EDC} \cdot \mathrm{HCl}(780 \mathrm{mg}, 4 \mathrm{mmol})$ and $\mathrm{NEt}_{3}(4 \mathrm{mmol}$, $0.4 \mathrm{~mL})$, stirred at room temperature for $1 \mathrm{~h}$. Then the corresponding amine $(6.0 \mathrm{mmol}, 3$ equiv.) was added to the reaction solution with stirring for $3 \mathrm{~h}$. The reaction mixture was acidified with dilute $\mathrm{HCl}$ to $\mathrm{pH} 7-8$ and extracted with EtOAc. The organic phase was washed with saturated sodium bicarbonate solution for twice, then dried over anhydrous $\mathrm{Na}_{2} \mathrm{SO}_{4}$, filtered, and concentrated under the reduced pressure. The residue was recrystallized from ethanol and $\mathrm{CH}_{2} \mathrm{Cl}_{2}$ to obtain the amides $4 \mathbf{a}-\mathbf{l}$, $\mathbf{5 a}-\mathbf{b}, \mathbf{6 a}, \mathbf{6 f}$. The residues of $\mathbf{6 b}-\mathbf{e}, \mathbf{7} \mathbf{a}-\mathbf{c}$ were purified by flash column chromatography $\left(\mathrm{CHCl}_{3} / \mathrm{EtOAc}\right.$ $=5 / 1, v / v$ ) [25] (white crystals or powder, yields $36-80 \%$ for this reaction step, Scheme 1 ).

\section{7-O-(2-(Methylamino)-2-oxoethyl)hesperetin (4a)}

White crystals, $72 \%$ yield, m.p. $179.8-182.7^{\circ} \mathrm{C} ;{ }^{1} \mathrm{H}-\mathrm{NMR}: \delta 12.08$ (s, 1H, 5-OH), 9.13 (s, 1H, 3'-OH), $8.07(\mathrm{~d}, J=4.5 \mathrm{~Hz}, 1 \mathrm{H}, \mathrm{NH}), 6.97-6.92\left(\mathrm{~m}, 2 \mathrm{H}, 2^{\prime}-\mathrm{H}, 5^{\prime}-\mathrm{H}\right), 6.88\left(\mathrm{dd}, J=8.4,1.8 \mathrm{~Hz}, 1 \mathrm{H}, 6^{\prime}-\mathrm{H}\right), 6.11$ $(\mathrm{d}, J=2.2 \mathrm{~Hz}, 1 \mathrm{H}, 8-\mathrm{H}), 6.10(\mathrm{~d}, J=2.2 \mathrm{~Hz}, 1 \mathrm{H}, 6-\mathrm{H}), 5.49(\mathrm{dd}, J=12.5,2.9 \mathrm{~Hz}, 1 \mathrm{H}, 2-\mathrm{H}), 4.54(\mathrm{~s}, 2 \mathrm{H}$, $\left.\mathrm{ArOCH}_{2} \mathrm{C}=\mathrm{O}\right), 3.78\left(\mathrm{~s}, 3 \mathrm{H}, \mathrm{OCH}_{3}\right), 3.27(\mathrm{dd}, J=17.1,12.5 \mathrm{~Hz}, 1 \mathrm{H}, 3-\mathrm{H}), 2.75(\mathrm{dd}, J=17.1,3.0 \mathrm{~Hz}, 1 \mathrm{H}$, 3-H), $2.65\left(\mathrm{~d}, J=4.6 \mathrm{~Hz}, 3 \mathrm{H}, \mathrm{NCH}_{3}\right) .{ }^{13} \mathrm{C}-\mathrm{NMR}: \delta 197.41,167.61,166.09,163.48,163.13,148.41,146.93$, 131.36, 118.21, 114.56, 112.38, 103.42, 95.84, 94.85, 78.94, 67.49, 56.11, 42.59, 25.82. HRMS (ESI): Calcd. $\mathrm{C}_{19} \mathrm{H}_{19} \mathrm{NO}_{7},[\mathrm{M}+\mathrm{H}]^{+} m / z: 374.1234$, found: 374.1241 .

7-O-(2-(Ethylamino)-2-oxoethyl)hesperetin (4b)

White crystals, $75 \%$ yield, m.p. $171.2-173.6{ }^{\circ} \mathrm{C} ;{ }^{1} \mathrm{H}-\mathrm{NMR}: \delta 12.08$ (s, $\left.1 \mathrm{H}, 5-\mathrm{OH}\right), 9.13\left(\mathrm{~s}, 1 \mathrm{H}, 3^{\prime}-\mathrm{OH}\right)$, $8.14(\mathrm{t}, J=5.5 \mathrm{~Hz}, 1 \mathrm{H}, \mathrm{NH}), 6.95-6.93\left(\mathrm{~m}, 2 \mathrm{H}, 2^{\prime}-\mathrm{H}, 5^{\prime}-\mathrm{H}\right), 6.88\left(\mathrm{dd}, J=8.4,1.8 \mathrm{~Hz}, 1 \mathrm{H}, 6^{\prime}-\mathrm{H}\right), 6.12$ $(\mathrm{d}, J=2.2 \mathrm{~Hz}, 1 \mathrm{H}, 8-\mathrm{H}), 6.10(\mathrm{~d}, J=2.2 \mathrm{~Hz}, 1 \mathrm{H}, 6-\mathrm{H}), 5.49(\mathrm{dd}, J=12.4,2.9 \mathrm{~Hz}, 1 \mathrm{H}, 2-\mathrm{H}), 4.53(\mathrm{~s}, 2 \mathrm{H}$, $\left.\mathrm{ArOCH}_{2} \mathrm{C}=\mathrm{O}\right), 3.78\left(\mathrm{~s}, 3 \mathrm{H}, \mathrm{OCH}_{3}\right), 3.27(\mathrm{dd}, J=17.2,12.5 \mathrm{~Hz}, 1 \mathrm{H}, 3-\mathrm{H}), 3.19-3.10\left(\mathrm{~m}, 2 \mathrm{H}, \mathrm{NCH}_{2}\right), 2.76$ $(\mathrm{dd}, J=17.1,3.0 \mathrm{~Hz}, 1 \mathrm{H}, 3-\mathrm{H}), 1.04\left(\mathrm{t}, J=7.2 \mathrm{~Hz}, 3 \mathrm{H}, \mathrm{NCCH}_{3}\right) .{ }^{13} \mathrm{C}-\mathrm{NMR}: \delta 197.39,166.86,166.16$, 163.48, 163.11, 148.41, 146.93, 131.37, 118.19, 114.55, 112.38, 103.41, 95.82, 94.88, 78.93, 67.48, 56.10, 42.58, 33.71, 15.18. HRMS (ESI): Calcd. $\mathrm{C}_{20} \mathrm{H}_{21} \mathrm{NO}_{7},[\mathrm{M}+\mathrm{H}]^{+} \mathrm{m} / z: 388.1391$, found: 388.1403 .

\section{7-O-(2-(Dimethylamino)-2-oxoethyl)hesperetin (4c)}

White crystals, 58\% yield, m.p. $164.1-165.8^{\circ} \mathrm{C} ;{ }^{1} \mathrm{H}-\mathrm{NMR}: \delta 12.08$ (s, 1H, 5-OH), $9.13\left(\mathrm{~s}, 1 \mathrm{H}, 3^{\prime}-\mathrm{OH}\right)$, 6.95-6.93 (m, 2H, 2'-H, 5'-H), 6.91-6.86 (m, 1H, 6'-H), $6.09(\mathrm{~d}, J=2.1 \mathrm{~Hz}, 1 \mathrm{H}, 8-\mathrm{H}), 6.07(\mathrm{~d}, J=2.1 \mathrm{~Hz}$, $1 \mathrm{H}, 6-\mathrm{H}), 5.47(\mathrm{dd}, J=12.6,2.7 \mathrm{~Hz}, 1 \mathrm{H}, 2-\mathrm{H}), 4.91\left(\mathrm{~s}, 2 \mathrm{H}, \mathrm{ArOCH}_{2} \mathrm{C}=\mathrm{O}\right), 3.78\left(\mathrm{~s}, 3 \mathrm{H}, \mathrm{OCH}_{3}\right), 3.26(\mathrm{dd}$, $J=17.1,12.7 \mathrm{~Hz}, 1 \mathrm{H}, 3-\mathrm{H}), 2.95\left(\mathrm{~s}, 3 \mathrm{H}, \mathrm{NCH}_{3}\right), 2.83\left(\mathrm{~s}, 3 \mathrm{H}, \mathrm{NCH}_{3}\right), 2.73(\mathrm{dd}, J=17.1,2.9 \mathrm{~Hz}, 1 \mathrm{H}, 3-\mathrm{H})$. ${ }^{13}$ C-NMR: $\delta$ 197.29, 166.87, 166.71, 163.42, 163.07, 148.41, 146.93, 131.41, 118.24, 114.59, 112.37, 103.16, 
95.86, 94.83, 78.96, 66.18, 56.11, 42.62, 35.80, 35.41. HRMS (ESI): Calcd. $\mathrm{C}_{20} \mathrm{H}_{21} \mathrm{NO}_{7},[\mathrm{M}+\mathrm{H}]^{+} m / z$ : 388.1391, found: 388.1401 .

\section{7-O-(2-(Propylamino)-2-oxoethyl)hesperetin (4d)}

White powder, $76 \%$ yield, m.p. $135.5-137.7{ }^{\circ} \mathrm{C} ;{ }^{1} \mathrm{H}-\mathrm{NMR}: \delta 12.08$ (s, 1H, 5-OH), $9.13\left(\mathrm{~s}, 1 \mathrm{H}, 3^{\prime}-\mathrm{OH}\right)$, $8.12(\mathrm{t}, J=5.6 \mathrm{~Hz}, 1 \mathrm{H}, \mathrm{NH}), 6.95-6.93\left(\mathrm{~m}, 2 \mathrm{H}, 2^{\prime}-\mathrm{H}, 5^{\prime}-\mathrm{H}\right), 6.88\left(\mathrm{dd}, J=8.4,1.7 \mathrm{~Hz}, 1 \mathrm{H}, 6^{\prime}-\mathrm{H}\right), 6.11$ $(\mathrm{d}, J=2.2 \mathrm{~Hz}, 1 \mathrm{H}, 8-\mathrm{H}), 6.09(\mathrm{~d}, J=2.2 \mathrm{~Hz}, 1 \mathrm{H}, 6-\mathrm{H}), 5.49(\mathrm{dd}, J=12.4,2.8 \mathrm{~Hz}, 1 \mathrm{H}, 2-\mathrm{H}), 4.54(\mathrm{~s}, 2 \mathrm{H}$, $\left.\mathrm{ArOCH}_{2} \mathrm{C}=\mathrm{O}\right), 3.78\left(\mathrm{~s}, 3 \mathrm{H}, \mathrm{OCH}_{3}\right), 3.27(\mathrm{dd}, J=17.1,12.5 \mathrm{~Hz}, 1 \mathrm{H}, 3-\mathrm{H}), 3.08(\mathrm{dd}, J=13.2,6.6 \mathrm{~Hz}, 2 \mathrm{H}$, $\left.\mathrm{NCH}_{2}\right), 2.76(\mathrm{dd}, J=17.1,3.0 \mathrm{~Hz}, 1 \mathrm{H}, 3-\mathrm{H}), 1.52-1.36\left(\mathrm{~m}, 2 \mathrm{H}, \mathrm{NCCH}_{2}\right), 0.83\left(\mathrm{t}, J=7.4 \mathrm{~Hz}, 3 \mathrm{H}, \mathrm{NCCCH}_{3}\right)$. ${ }^{13}$ C-NMR: $\delta 197.38,167.06,166.21,163.48,163.10,148.40,146.93,131.37,118.18,114.55,112.37,103.39$, 95.80, 94.89, 78.92, 67.46, 56.10, 42.58, 40.57, 22.79, 11.78. HRMS (ESI): Calcd. $\mathrm{C}_{21} \mathrm{H}_{23} \mathrm{NO}_{7},[\mathrm{M}+\mathrm{H}]^{+}$ $m / z: 402.1557$, found: 402.1562 .

\section{7-O-(2-(Isopropylamino)-2-oxoethyl)hesperetin (4e)}

White powder, 73\% yield, m.p. $157.6-160.4{ }^{\circ} \mathrm{C} ;{ }^{1} \mathrm{H}-\mathrm{NMR}: \delta 12.08$ (s, 1H, 5-OH), $9.13(\mathrm{~s}, 1 \mathrm{H}, 3$ '-OH), $7.96(\mathrm{~d}, J=7.8 \mathrm{~Hz}, 1 \mathrm{H}, \mathrm{NH}), 6.95-6.93\left(\mathrm{~m}, 2 \mathrm{H}, 2^{\prime}-\mathrm{H}, 5^{\prime}-\mathrm{H}\right), 6.88\left(\mathrm{dd}, J=8.3,1.8 \mathrm{~Hz}, 1 \mathrm{H}, 6^{\prime}-\mathrm{H}\right), 6.11$ $(\mathrm{d}, J=2.2 \mathrm{~Hz}, 1 \mathrm{H}, 8-\mathrm{H}), 6.09(\mathrm{~d}, J=2.2 \mathrm{~Hz}, 1 \mathrm{H}, 6-\mathrm{H}), 5.49(\mathrm{dd}, J=12.3,2.9 \mathrm{~Hz}, 1 \mathrm{H}, 2-\mathrm{H}), 4.51(\mathrm{~s}$, $\left.2 \mathrm{H}, \mathrm{ArOCH}_{2} \mathrm{C}=\mathrm{O}\right), 3.92(\mathrm{dq}, J=13.4,6.6 \mathrm{~Hz}, 1 \mathrm{H}, \mathrm{CHNC}=\mathrm{O}), 3.78\left(\mathrm{~s}, 3 \mathrm{H}, \mathrm{OCH}_{3}\right), 3.27(\mathrm{dd}, J=17.1$, $12.4 \mathrm{~Hz}, 1 \mathrm{H}, 3-\mathrm{H}), 2.76(\mathrm{dd}, J=17.1,3.0 \mathrm{~Hz}, 1 \mathrm{H}, 3-\mathrm{H}), 1.09\left(\mathrm{~d}, J=6.6 \mathrm{~Hz}, 6 \mathrm{H},\left(\mathrm{CH}_{3}\right)_{2} \mathrm{CN}\right) .{ }^{13} \mathrm{C}-\mathrm{NMR}: \delta$ 197.36, 166.31, 166.11, 163.49, 163.08, 148.39, 146.93, 131.39, 118.17, 114.54, 112.37, 103.37, 95.77, 94.89, 78.90, 67.44, 56.09, 42.58, 40.85, 22.68, 22.68. HRMS (ESI): Calcd. $\mathrm{C}_{21} \mathrm{H}_{23} \mathrm{NO}_{7},[\mathrm{M}+\mathrm{H}]^{+} m / z: 402.1557$, found: 402.1562 .

\section{7-O-(2-(Butylamino)-2-oxoethyl)hesperetin (4f)}

White powder, 80\% yield, m.p. 136.9-138.4 ${ }^{\circ} \mathrm{C} ;{ }^{1} \mathrm{H}-\mathrm{NMR}: \delta 12.08$ (s, 1H, 5-OH), $9.13\left(\mathrm{~s}, 1 \mathrm{H}, 33^{\prime}-\mathrm{OH}\right)$, $8.10(\mathrm{t}, J=5.7 \mathrm{~Hz}, 1 \mathrm{H}, \mathrm{NH}), 6.94\left(\mathrm{dd}, J=5.1,3.2 \mathrm{~Hz}, 2 \mathrm{H}, 2^{\prime}-\mathrm{H}, 5^{\prime}-\mathrm{H}\right), 6.88\left(\mathrm{dd}, J=8.4,1.8 \mathrm{~Hz}, 1 \mathrm{H}, 6^{\prime}-\mathrm{H}\right)$, $6.11(\mathrm{~d}, J=2.2 \mathrm{~Hz}, 1 \mathrm{H}, 8-\mathrm{H}), 6.09(\mathrm{~d}, J=2.2 \mathrm{~Hz}, 1 \mathrm{H}, 6-\mathrm{H}), 5.49(\mathrm{dd}, J=12.4,2.9 \mathrm{~Hz}, 1 \mathrm{H}, 2-\mathrm{H}), 4.54(\mathrm{~s}, 2 \mathrm{H}$, $\left.\mathrm{ArOCH}_{2} \mathrm{C}=\mathrm{O}\right), 3.78\left(\mathrm{~s}, 3 \mathrm{H}, \mathrm{OCH}_{3}\right), 3.26(\mathrm{dd}, J=17.1,12.5 \mathrm{~Hz}, 1 \mathrm{H}, 3-\mathrm{H}), 3.11(\mathrm{dd}, J=13.0,6.7 \mathrm{~Hz}, 2 \mathrm{H}$, $\left.\mathrm{NCH}_{2}\right), 2.76(\mathrm{dd}, J=17.1,3.0 \mathrm{~Hz}, 1 \mathrm{H}, 3-\mathrm{H}), 1.46-1.34\left(\mathrm{~m}, 2 \mathrm{H}, \mathrm{NCCH}_{2}\right), 1.33-1.18\left(\mathrm{~m}, 2 \mathrm{H}, \mathrm{NCCCH}_{2}\right)$, $0.86\left(\mathrm{t}, J=7.3 \mathrm{~Hz}, 3 \mathrm{H}, \mathrm{NCCCCH}_{3}\right) .{ }^{13} \mathrm{C}-\mathrm{NMR}: \delta 197.37,167.01,166.21,163.49,163.11,148.40,146.93$, $131.38,118.17,114.54,112.37,103.38,95.82,94.87,78.94,67.47,56.10,42.60,38.46,31.62,19.97,14.11$. HRMS (ESI): Calcd. $\mathrm{C}_{22} \mathrm{H}_{25} \mathrm{NO}_{7},[\mathrm{M}+\mathrm{H}]^{+} \mathrm{m} / \mathrm{z}: 416.1704$, found: 416.1717.

7-O-(2-(Isobutylamino)-2-oxoethyl)hesperetin (4g)

White powder, 77\% yield, m.p. 136.9-139.4 ${ }^{\circ} \mathrm{C} ;{ }^{1} \mathrm{H}-\mathrm{NMR}: \delta 12.08$ (s, 1H, 5-OH), 9.12 (s, 1H, 3'-OH), $8.12(\mathrm{t}, J=5.9 \mathrm{~Hz}, 1 \mathrm{H}, \mathrm{NH}), 6.97-6.91\left(\mathrm{~m}, 2 \mathrm{H}, 2^{\prime}-\mathrm{H}, 5^{\prime}-\mathrm{H}\right), 6.88\left(\mathrm{dd}, J=8.4,1.7 \mathrm{~Hz}, 1 \mathrm{H}, 6^{\prime}-\mathrm{H}\right), 6.11$ $(\mathrm{d}, J=2.2 \mathrm{~Hz}, 1 \mathrm{H}, 8-\mathrm{H}), 6.09(\mathrm{~d}, J=2.2 \mathrm{~Hz}, 1 \mathrm{H}, 6-\mathrm{H}), 5.49(\mathrm{dd}, J=12.4,2.9 \mathrm{~Hz}, 1 \mathrm{H}, 2-\mathrm{H}), 4.57(\mathrm{~s}, 2 \mathrm{H}$, $\left.\mathrm{ArOCH}_{2} \mathrm{C}=\mathrm{O}\right), 3.78\left(\mathrm{~s}, 3 \mathrm{H}, \mathrm{OCH}_{3}\right), 3.26(\mathrm{dd}, J=17.1,12.5 \mathrm{~Hz}, 1 \mathrm{H}, 3-\mathrm{H}), 2.94\left(\mathrm{t}, J=6.4 \mathrm{~Hz}, 2 \mathrm{H}, \mathrm{NCH}_{2}\right)$, $2.76(\mathrm{dd}, J=17.1,3.0 \mathrm{~Hz}, 1 \mathrm{H}, 3-\mathrm{H}), 1.72\left(\mathrm{dp}, J=13.4,6.7 \mathrm{~Hz}, 1 \mathrm{H}, \mathrm{NCCHC}_{2}\right), 0.83(\mathrm{~d}, J=6.7 \mathrm{~Hz}, 6 \mathrm{H}$, $\left.\mathrm{NCC}\left(\mathrm{CH}_{3}\right)_{2}\right) .{ }^{13} \mathrm{C}-\mathrm{NMR}: \delta 197.37,167.15,166.26,163.49,163.09,148.39,146.93,131.38,118.16,114.54$, 112.37, 103.37, 95.78, 94.90, 78.92, 67.45, 56.10, 46.26, 42.59, 28.51, 20.50, 20.50. HRMS (ESI): Calcd. $\mathrm{C}_{22} \mathrm{H}_{25} \mathrm{NO}_{7},[\mathrm{M}+\mathrm{H}]^{+} m / z: 416.1704$, found: 416.1716 .

7-O-(2-(tert-Butylamino)-2-oxoethyl)hesperetin (4h)

White powder, 53\% yield, m.p. $140.5-142.4{ }^{\circ} \mathrm{C} ;{ }^{1} \mathrm{H}-\mathrm{NMR}: \delta 12.08$ (s, 1H, 5-OH), $9.13\left(\mathrm{~s}, 1 \mathrm{H}, 3^{\prime}-\mathrm{OH}\right)$, $7.61(\mathrm{br}, 1 \mathrm{H}, \mathrm{NH}), 6.97-6.91\left(\mathrm{~m}, 2 \mathrm{H}, 2^{\prime}-\mathrm{H}, 5^{\prime}-\mathrm{H}\right), 6.88\left(\mathrm{dd}, J=8.4,1.7 \mathrm{~Hz}, 1 \mathrm{H}, 6^{\prime}-\mathrm{H}\right), 6.08(\mathrm{~d}, J=2.2 \mathrm{~Hz}$, $1 \mathrm{H}, 8-\mathrm{H}), 6.06(\mathrm{~d}, J=2.2 \mathrm{~Hz}, 1 \mathrm{H}, 6-\mathrm{H}), 5.49(\mathrm{dd}, J=12.3,2.9 \mathrm{~Hz}, 1 \mathrm{H}, 2-\mathrm{H}), 4.48\left(\mathrm{~s}, 2 \mathrm{H}, \mathrm{ArOCH}_{2} \mathrm{C}=\mathrm{O}\right)$, $3.78\left(\mathrm{~s}, 3 \mathrm{H}, \mathrm{OCH}_{3}\right), 3.26(\mathrm{dd}, J=17.1,12.4 \mathrm{~Hz}, 1 \mathrm{H}, 3-\mathrm{H}), 2.76(\mathrm{dd}, J=17.1,3.0 \mathrm{~Hz}, 1 \mathrm{H}, 3-\mathrm{H}), 1.28(\mathrm{~s}, 9 \mathrm{H}$, $\left.\mathrm{NC}\left(\mathrm{CH}_{3}\right)_{3}\right) .{ }^{13} \mathrm{C}-\mathrm{NMR}: \delta 197.33,166.48,166.41,163.51,163.07,148.39,146.93,131.39,118.18,114.54$, 
112.38, 103.31, 95.61, 94.84, 78.89, 67.51, 56.09, 50.89, 42.57, 28.87, 28.87, 28.87. HRMS (ESI): Calcd. $\mathrm{C}_{22} \mathrm{H}_{25} \mathrm{NO}_{7},[\mathrm{M}+\mathrm{H}]^{+} m / z: 416.1704$, found: 416.1717 .

7-O-(2-(Diethylamino)-2-oxoethyl)hesperetin (4i)

White powder, $46 \%$ yield, m.p. $146.3-147.8^{\circ} \mathrm{C} ;{ }^{1} \mathrm{H}-\mathrm{NMR}: \delta 12.08$ (s, 1H, 5-OH), 9.13 (s, 1H, 3'-OH), 6.97-6.91 (m, 2H, 2'-H, 5'-H), $6.89\left(\mathrm{~d}, J=8.2 \mathrm{~Hz}, 1 \mathrm{H}, 6^{\prime}-\mathrm{H}\right), 6.08(\mathrm{~d}, J=1.9 \mathrm{~Hz}, 1 \mathrm{H}, 8-\mathrm{H}), 6.05(\mathrm{~d}$, $J=1.9 \mathrm{~Hz}, 1 \mathrm{H}, 6-\mathrm{H}), 5.48(\mathrm{dd}, J=12.5,2.4 \mathrm{~Hz}, 1 \mathrm{H}, 2-\mathrm{H}), 4.88\left(\mathrm{~s}, 2 \mathrm{H}, \mathrm{ArOCH}_{2} \mathrm{C}=\mathrm{O}\right), 3.78\left(\mathrm{~s}, 3 \mathrm{H}, \mathrm{OCH}_{3}\right)$, 3.34-3.20 (m, 5H, N( $\left.\left.\mathrm{CH}_{2} \mathrm{C}\right)_{2}, 3-\mathrm{H}\right), 2.73(\mathrm{dd}, J=17.1,2.7 \mathrm{~Hz}, 1 \mathrm{H}, 3-\mathrm{H}), 1.13\left(\mathrm{t}, J=7.0 \mathrm{~Hz}, 3 \mathrm{H}, \mathrm{NCCH}_{3}\right)$, $1.02\left(\mathrm{t}, J=7.0 \mathrm{~Hz}, 3 \mathrm{H}, \mathrm{NCCH}_{3}\right) .{ }^{13} \mathrm{C}-\mathrm{NMR}: \delta 197.29,166.83,165.82,163.45,163.08,148.41,146.93,131.40$, $118.23,114.58,112.37,103.19,95.78,94.85,79.65,78.96,66.38,56.10,42.62,40.86,14.53,13.33$. HRMS (ESI): Calcd. $\mathrm{C}_{22} \mathrm{H}_{25} \mathrm{NO}_{7},[\mathrm{M}+\mathrm{H}]^{+} m / z: 416.1704$, found: 416.1714 .

7-O-(2-(Cyclopropylamino)-2-oxoethyl)hesperetin ( $4 \mathbf{j})$

White powder, 66\% yield, m.p. $\left.190.8-193.1{ }^{\circ} \mathrm{C} ;{ }^{1} \mathrm{H}-\mathrm{NMR}:\right) \delta 12.08$ (s, 1H, 5-OH), $9.13(\mathrm{~s}, 1 \mathrm{H}$, $\left.3^{\prime}-\mathrm{OH}\right), 8.17(\mathrm{~d}, J=4.0 \mathrm{~Hz}, 1 \mathrm{H}, \mathrm{NH}), 6.95-6.93\left(\mathrm{~m}, 2 \mathrm{H}, 2^{\prime}-\mathrm{H}, 5^{\prime}-\mathrm{H}\right), 6.88\left(\mathrm{dd}, J=8.4,1.7 \mathrm{~Hz}, 1 \mathrm{H}, 6^{\prime}-\mathrm{H}\right)$, $6.10(\mathrm{~d}, J=2.2 \mathrm{~Hz}, 1 \mathrm{H}, 8-\mathrm{H}), 6.08(\mathrm{~d}, J=2.2 \mathrm{~Hz}, 1 \mathrm{H}, 6-\mathrm{H}), 5.49(\mathrm{dd}, J=12.4,2.8 \mathrm{~Hz}, 1 \mathrm{H}, 2-\mathrm{H}), 4.51(\mathrm{~s}, 2 \mathrm{H}$, $\left.\mathrm{ArOCH}_{2} \mathrm{C}=\mathrm{O}\right), 3.78\left(\mathrm{~s}, 3 \mathrm{H}, \mathrm{OCH}_{3}\right), 3.27(\mathrm{dd}, J=17.1,12.5 \mathrm{~Hz}, 1 \mathrm{H}, 3-\mathrm{H}), 2.76(\mathrm{dd}, J=17.1,3.0 \mathrm{~Hz}, 1 \mathrm{H}$, 3-H), 2.72-2.64 (m, 1H, NCH), 0.68-0.60 (m, 2H, NCCH $), 0.51-0.43\left(\mathrm{~m}, 2 \mathrm{H}, \mathrm{NCCH}_{2}\right) .{ }^{13} \mathrm{C}-\mathrm{NMR}: \delta$ $197.38,168.33,166.24,163.46,163.09,148.40,146.93,131.37,118.19,114.55,112.37,103.38,95.78,94.84$, 78.92, 67.37, 56.09, 42.58, 22.64, 6.05, 6.05. HRMS (ESI): Calcd. $\mathrm{C}_{21} \mathrm{H}_{21} \mathrm{NO}_{7},[\mathrm{M}+\mathrm{H}]^{+} m / z: 400.1401$, found: 400.1407 .

7-O-(2-(Cyclopentylamino)-2-oxoethyl)hesperetin (4k)

White powder, 79\% yield, m.p. $187.5-190.0{ }^{\circ} \mathrm{C} ;{ }^{1} \mathrm{H}-\mathrm{NMR}: \delta 12.08(\mathrm{~s}, 1 \mathrm{H}, 5-\mathrm{OH}), 9.13\left(\mathrm{~s}, 1 \mathrm{H}, 3^{\prime}-\mathrm{OH}\right)$, $8.04(\mathrm{~d}, J=7.4 \mathrm{~Hz}, 1 \mathrm{H}, \mathrm{NH}), 6.95-6.93\left(\mathrm{~m}, 2 \mathrm{H}, 2^{\prime}-\mathrm{H}, 5^{\prime}-\mathrm{H}\right), 6.88\left(\mathrm{dd}, J=8.4,1.7 \mathrm{~Hz}, 1 \mathrm{H}, 6^{\prime}-\mathrm{H}\right), 6.10$ $(\mathrm{d}, J=2.2 \mathrm{~Hz}, 1 \mathrm{H}, 8-\mathrm{H}), 6.08(\mathrm{~d}, J=2.2 \mathrm{~Hz}, 1 \mathrm{H}, 6-\mathrm{H}), 5.49(\mathrm{dd}, J=12.3,2.8 \mathrm{~Hz}, 1 \mathrm{H}, 2-\mathrm{H}), 4.52(\mathrm{~s}, 2 \mathrm{H}$, $\left.\mathrm{ArOCH}_{2} \mathrm{C}=\mathrm{O}\right), 4.12-3.99(\mathrm{~m}, 1 \mathrm{H}, \mathrm{NCH}), 3.78\left(\mathrm{~s}, 3 \mathrm{H}, \mathrm{OCH}_{3}\right), 3.26(\mathrm{dd}, J=17.1,12.4 \mathrm{~Hz}, 1 \mathrm{H}, 3-\mathrm{H}), 2.76$ $(\mathrm{dd}, J=17.1,3.0 \mathrm{~Hz}, 1 \mathrm{H}, 3-\mathrm{H}), 1.80\left(\mathrm{dt}, J=12.6,6.1 \mathrm{~Hz}, 2 \mathrm{H}, \mathrm{NCCH}_{2}\right), 1.72-1.58\left(\mathrm{~m}, 2 \mathrm{H}, \mathrm{NCCH}_{2}\right)$, 1.56-1.46 (m, 2H, $\left.\mathrm{NCCCH}_{2}\right), 1.46-1.34\left(\mathrm{~m}, 2 \mathrm{H}, \mathrm{NCCCH}_{2}\right) .{ }^{13} \mathrm{C}-\mathrm{NMR}: \delta 197.35,166.54,166.37,163.49$, $163.08,148.39,146.93,131.39,118.17,114.54,112.36,103.34,95.73,94.87,78.90,67.42,56.09,50.63,42.58$, 32.54, 32.54, 23.92, 23.92. HRMS (ESI): Calcd. $\mathrm{C}_{23} \mathrm{H}_{25} \mathrm{NO}_{7},[\mathrm{M}+\mathrm{H}]^{+} \mathrm{m} / z: 428.1714$, found: 428.1723 .

7-O-(2-(Cyclohexylamino)-2-oxoethyl)hesperetin (41)

White powder, $80 \%$ yield, m.p. $181.9-184.1^{\circ} \mathrm{C} ;{ }^{1} \mathrm{H}-\mathrm{NMR}: \delta 12.08$ (s, $\left.1 \mathrm{H}, 5-\mathrm{OH}\right), 9.13\left(\mathrm{~s}, 1 \mathrm{H}, 3^{\prime}-\mathrm{OH}\right)$, $7.95(\mathrm{~d}, J=8.0 \mathrm{~Hz}, 1 \mathrm{H}, \mathrm{NH}), 6.95-6.93\left(\mathrm{~m}, 2 \mathrm{H}, 2^{\prime}-\mathrm{H}, 5^{\prime}-\mathrm{H}\right), 6.88\left(\mathrm{dd}, J=8.4,1.7 \mathrm{~Hz}, 1 \mathrm{H}, 6^{\prime}-\mathrm{H}\right), 6.11$ $(\mathrm{d}, J=2.1 \mathrm{~Hz}, 1 \mathrm{H}, 8-\mathrm{H}), 6.09(\mathrm{~d}, J=2.2 \mathrm{~Hz}, 1 \mathrm{H}, 6-\mathrm{H}), 5.49(\mathrm{dd}, J=12.3,2.8 \mathrm{~Hz}, 1 \mathrm{H}, 2-\mathrm{H}), 4.53(\mathrm{~s}, 2 \mathrm{H}$, $\left.\mathrm{ArOCH}_{2} \mathrm{C}=\mathrm{O}\right), 3.78\left(\mathrm{~s}, 3 \mathrm{H}, \mathrm{OCH}_{3}\right), 3.60(\mathrm{~m}, 1 \mathrm{H}, \mathrm{NCH}), 3.26(\mathrm{dd}, J=17.1,12.4 \mathrm{~Hz}, 1 \mathrm{H}, 3-\mathrm{H}), 2.76(\mathrm{dd}$, $J=17.1,3.0 \mathrm{~Hz}, 1 \mathrm{H}, 3-\mathrm{H}), 1.78-1.62\left(\mathrm{~m}, 4 \mathrm{H}, \mathrm{NC}\left(\mathrm{CH}_{2}\right)_{2}\right), 1.57-1.54(\mathrm{~m}, 1 \mathrm{H}, \mathrm{NCCCCH}), 1.34-1.18(\mathrm{~m}, 4 \mathrm{H}$, $\left.\mathrm{NCC}\left(\mathrm{CH}_{2}\right)_{2}\right), 1.15-1.09$ (m, 1H, NCCCCH). ${ }^{13} \mathrm{C}-\mathrm{NMR}: \delta 197.35,166.33,166.07,163.49,163.07,148.39$, 146.93, 131.39, 118.16, 114.54, 112.36, 103.35, 95.74, 94.89, 78.90, 67.42, 56.09, 47.96, 42.58, 32.71, 32.71, 25.61, 25.07, 25.07. HRMS (ESI): Calcd. $\mathrm{C}_{24} \mathrm{H}_{27} \mathrm{NO}_{7}$, [M + H] ${ }^{+} \mathrm{m} / z: 442.1860$, found: 442.1870 .

7-O-(2-(Pyrrolidin-1-yl)-2-oxoethyl)hesperetin (5a)

White powder, $74 \%$ yield, m.p. $127.1-130.5^{\circ} \mathrm{C} ;{ }^{1} \mathrm{H}-\mathrm{NMR}: \delta 12.08$ (s, $\left.1 \mathrm{H}, 5-\mathrm{OH}\right), 9.13\left(\mathrm{~s}, 1 \mathrm{H}, 3^{\prime}-\mathrm{OH}\right)$, 6.95-6.93 (m, 2H, 2'-H, 5'-H), $6.89\left(\mathrm{dd}, J=8.4,1.8 \mathrm{~Hz}, 1 \mathrm{H}, 6^{\prime}-\mathrm{H}\right), 6.09(\mathrm{~d}, J=2.3 \mathrm{~Hz}, 1 \mathrm{H}, 8-\mathrm{H}), 6.07$ $(\mathrm{d}, J=2.3 \mathrm{~Hz}, 1 \mathrm{H}, 6-\mathrm{H}), 5.47(\mathrm{dd}, J=12.7,2.8 \mathrm{~Hz}, 1 \mathrm{H}, 2-\mathrm{H}), 4.81\left(\mathrm{~s}, 2 \mathrm{H}, \mathrm{ArOCH}_{2} \mathrm{C}=\mathrm{O}\right), 3.78(\mathrm{~s}, 3 \mathrm{H}$, $\left.\mathrm{OCH}_{3}\right), 3.42\left(\mathrm{t}, J=6.8 \mathrm{~Hz}, 2 \mathrm{H}, \mathrm{CH}_{2} \mathrm{NC}=\mathrm{O}\right), 3.30\left(\mathrm{t}, J=6.8 \mathrm{~Hz}, 2 \mathrm{H}, \mathrm{CH}_{2} \mathrm{NC}=\mathrm{O}\right), 3.26((\mathrm{dd}, J=17.1$, $12.4 \mathrm{~Hz}, 1 \mathrm{H}, 3-\mathrm{H}), 2.72(\mathrm{dd}, J=17.1,3.0 \mathrm{~Hz}, 1 \mathrm{H}, 3-\mathrm{H}), 1.88\left(\mathrm{p}, J=6.7 \mathrm{~Hz}, 2 \mathrm{H}, \mathrm{CH}_{2} \mathrm{CNC}=\mathrm{O}\right), 1.81-1.71(\mathrm{p}$, $\left.J=6.7 \mathrm{~Hz}, 2 \mathrm{H}, \mathrm{CH}_{2} \mathrm{CNC}=\mathrm{O}\right) .{ }^{13} \mathrm{C}-\mathrm{NMR}: \delta 197.30,166.85,165.17,163.42,163.08,148.42,146.92,131.40$, 
118.26, 114.59, 112.36, 103.18, 95.85, 94.79, 78.98, 66.59, 56.11, 46.03, 44.93, 42.63, 26.07, 23.97. HRMS (ESI): Calcd. $\mathrm{C}_{22} \mathrm{H}_{23} \mathrm{NO}_{7},[\mathrm{M}+\mathrm{H}]^{+} \mathrm{m} / z$ : 414.1557, found: 414.1563 .

7-O-(2-(Thiazolidin-3-yl)-2-oxoethyl)hesperetin (5b)

White crystals, $76 \%$ yield, m.p. $152.4-154.7^{\circ} \mathrm{C} ;{ }^{1} \mathrm{H}-\mathrm{NMR}: \delta 12.08$ (s, $\left.1 \mathrm{H}, 5-\mathrm{OH}\right), 9.13\left(\mathrm{~s}, 1 \mathrm{H}, 3^{\prime}-\mathrm{OH}\right)$, 6.95-6.93 (m, 2H, 2'-H, $\left.5^{\prime}-\mathrm{H}\right), 6.89\left(\mathrm{dd}, J=8.3,1 \mathrm{H}, 6^{\prime}-\mathrm{H}\right), 6.13(\mathrm{~d}, J=2.2 \mathrm{~Hz}, 1 \mathrm{H}, 8-\mathrm{H}), 6.10(\mathrm{~d}, J=2.2 \mathrm{~Hz}$, $1 \mathrm{H}, 6-\mathrm{H}), 5.48(\mathrm{dd}, J=12.6,2.8 \mathrm{~Hz}, 1 \mathrm{H}, 2-\mathrm{H}), 4.94\left(\mathrm{~s}, 2 \mathrm{H}, \mathrm{ArOCH}_{2} \mathrm{C}=\mathrm{O}\right), 4.52\left(\mathrm{br}, 2 \mathrm{H}, \mathrm{SCH}_{2} \mathrm{~N}\right), 3.78(\mathrm{~s}$, $\left.\left.3 \mathrm{H}, \mathrm{OCH}_{3}\right), 3.72(\mathrm{t}, J=6.2 \mathrm{~Hz}, 1 \mathrm{H}, \mathrm{NCHCS}), 3.67(\mathrm{t}, J=6.3 \mathrm{~Hz}, 1 \mathrm{H}, \mathrm{NCHCS})\right), 3.27$ (dd, $J=17.1,12.7 \mathrm{~Hz}$, $1 \mathrm{H}, 3-\mathrm{H}), 3.11(\mathrm{t}, J=6.2 \mathrm{~Hz}, 1 \mathrm{H}, \mathrm{NCCHS}), 2.98(\mathrm{t}, J=6.3 \mathrm{~Hz}, 1 \mathrm{H}, \mathrm{NCCHS}), 2.73(\mathrm{dd}, J=17.1,3.0 \mathrm{~Hz}, 1 \mathrm{H}$, 3-H). ${ }^{13}$ C-NMR: $\delta$ 197.34, 166.67, 165.39, 163.43, 163.11, 148.42, 146.92, 131.38, 118.26, 114.59, 112.36, 103.25, 95.87, 94.83, 78.98, 66.61, 56.11, 48.59, 47.54, 42.62, 31.25. HRMS (ESI): Calcd. $\mathrm{C}_{21} \mathrm{H}_{21} \mathrm{NO}_{7} \mathrm{~S}$, [M + $\mathrm{H}]^{+} m / z: 432.1111$, found: 432.1126 .

7-O-(2-(piperidin-1-yl)-2-oxoethyl)hesperetin (6a)

White powder, 78\% yield, m.p. $165.4-167.9{ }^{\circ} \mathrm{C} ;{ }^{1} \mathrm{H}-\mathrm{NMR}: \delta 12.08$ (s, 1H, 5-OH), $9.13(\mathrm{~s}, 1 \mathrm{H}, 3$ '-OH), $6.94\left(\mathrm{~d}, J=7.1 \mathrm{~Hz}, 2 \mathrm{H}, 2^{\prime}-\mathrm{H}, 5^{\prime}-\mathrm{H}\right), 6.89\left(\mathrm{~d}, J=8.2 \mathrm{~Hz}, 1 \mathrm{H}, 6^{\prime}-\mathrm{H}\right), 6.08(\mathrm{~d}, J=2.1 \mathrm{~Hz}, 1 \mathrm{H}, 8-\mathrm{H}), 6.06(\mathrm{~d}$, $J=2.1 \mathrm{~Hz}, 1 \mathrm{H}, 6-\mathrm{H}), 5.48(\mathrm{dd}, J=12.3,2.1 \mathrm{~Hz}, 1 \mathrm{H}, 2-\mathrm{H}), 4.90\left(\mathrm{~s}, 2 \mathrm{H}, \mathrm{ArOCH}_{2} \mathrm{C}=\mathrm{O}\right), 3.78\left(\mathrm{~s}, 3 \mathrm{H}, \mathrm{OCH}_{3}\right)$, $3.41\left(\mathrm{~m}, 2 \mathrm{H}, \mathrm{NCH}_{2}\right), 3.34\left(\mathrm{~m}, 2 \mathrm{H}, \mathrm{NCH}_{2}\right), 3.26(\mathrm{dd}, J=17.0,12.8 \mathrm{~Hz}, 1 \mathrm{H}, 3-\mathrm{H}), 2.73(\mathrm{dd}, J=17.0,2.4 \mathrm{~Hz}$, 1H, 3-H), 1.70-1.34 (m, 6H, NC( $\left.\left.\mathrm{CH}_{2}\right)_{2} \mathrm{CH}_{2}\right) .{ }^{13} \mathrm{C}-\mathrm{NMR}: \delta 197.30,166.83,165.01,163.44,163.08,148.41$, 146.93, 131.41, 118.23, 114.58, 112.36, 103.18, 95.81, 94.83, 78.96, 66.47, 56.10, 45.42, 42.62, 42.62, 26.34, 25.72, 24.37. HRMS (ESI): Calcd. $\mathrm{C}_{23} \mathrm{H}_{25} \mathrm{NO}_{7},[\mathrm{M}+\mathrm{H}]^{+} \mathrm{m} / z$ : 428.1704 , found: 428.1718 .

7-O-(2-(3-(Hydroxymethyl)piperidin-1-yl)-2-oxoethyl)hesperetin (6b)

White powder, $40 \%$ yield, m.p. $168.6-171.8^{\circ} \mathrm{C} ;{ }^{1} \mathrm{H}-\mathrm{NMR}: \delta 12.08$ (s, 1H, 5-OH), $9.13\left(\mathrm{~s}, 1 \mathrm{H}, 3^{\prime}-\mathrm{OH}\right)$, 6.97-6.91 (m, 2H, 2'-H, 5'-H), $6.89\left(\mathrm{dd}, J=8.3,1.6 \mathrm{~Hz}, 1 \mathrm{H}, 6^{\prime}-\mathrm{H}\right), 6.08(\mathrm{~d}, J=2.3 \mathrm{~Hz}, 1 \mathrm{H}, 8-\mathrm{H}), 6.06(\mathrm{~d}$, $J=2.3 \mathrm{~Hz}, 1 \mathrm{H}, 6-\mathrm{H}), 5.48(\mathrm{dd}, J=12.5,2.5 \mathrm{~Hz}, 1 \mathrm{H}, 2-\mathrm{H}), 4.91\left(\mathrm{~s}, 2 \mathrm{H}, \mathrm{ArOCH}_{2} \mathrm{C}=\mathrm{O}\right), 4.61-4.55(\mathrm{~m}, 1 \mathrm{H}$, $\mathrm{OH}), 3.78\left(\mathrm{~s}, 3 \mathrm{H}, \mathrm{OCH}_{3}\right), 3.66\left(\mathrm{~d}, J=13.0 \mathrm{~Hz}, 1 \mathrm{H}, \mathrm{CH}_{2} \mathrm{OH}\right), 3.36\left(\mathrm{~m}, 1 \mathrm{H}, \mathrm{CH}_{2} \mathrm{OH}\right), 3.29-3.12(\mathrm{~m}, 3 \mathrm{H}, 3-\mathrm{H}$, $\left.\mathrm{NCH}_{2}\right), 3.01-2.77\left(\mathrm{~m}, 2 \mathrm{H}, \mathrm{NCH}_{2}\right), 2.73(\mathrm{dd}, J=17.1,2.8 \mathrm{~Hz}, 1 \mathrm{H}, 3-\mathrm{H}), 1.79-1.50\left(\mathrm{~m}, 3 \mathrm{H}, \mathrm{CHCH}_{2} \mathrm{CH}_{2}\right)$, 1.44-1.38 (m, $\left.1 \mathrm{H}, \mathrm{CHCH}_{2} \mathrm{CH}_{2}\right), 1.34-1.19\left(\mathrm{~m}, 1 \mathrm{H}, \mathrm{CHCH}_{2} \mathrm{CH}_{2}\right) .{ }^{13} \mathrm{C}-\mathrm{NMR}: \delta$ 197.29, 166.82, 165.09, $163.44,163.07,148.41,146.93,131.41,118.24,114.58,112.37,103.19,95.80,94.84,78.96,66.54,64.11$, 56.10, 47.60, 45.40, 42.63, 39.08, 27.23, 25.40. HR-MS (ESI): Calcd. $\mathrm{C}_{24} \mathrm{H}_{27} \mathrm{NO}_{8},[\mathrm{M}+\mathrm{H}]^{+} \mathrm{m} / \mathrm{z}: 458.1819$, found: 458.1828 .

7-O-(2-(2-(Hydroxymethyl)piperidin-1-yl)-2-oxoethyl)hesperetin (6c)

White powder, $36 \%$ yield, m.p. $123.2-125.8^{\circ} \mathrm{C} ;{ }^{1} \mathrm{H}-\mathrm{NMR}: \delta 12.08$ (s, 1H, 5-OH), $9.13\left(\mathrm{~s}, 1 \mathrm{H}, 3^{\prime}-\mathrm{OH}\right)$, 6.97-6.92 (m, 2H, 2'-H, 5'-H), 6.89 (dd, J = 8.4, 1.7 Hz, 1H, 6'-H), 6.07 (d, J = 15.6 Hz, 2H, 8-H, 6-H), 5.48 $(\mathrm{dd}, J=12.6,2.7 \mathrm{~Hz}, 1 \mathrm{H}, 2-\mathrm{H}), 4.92\left(\mathrm{~s}, 2 \mathrm{H}, \mathrm{ArOCH}_{2} \mathrm{C}=\mathrm{O}\right), 4.24(\mathrm{~d}, J=12.9 \mathrm{~Hz}, 1 \mathrm{H}, \mathrm{OH}), 3.91-3.71(\mathrm{~m}$, $\left.4 \mathrm{H}, \mathrm{OCH}_{3}, \mathrm{CH}_{2} \mathrm{OH}\right), 3.55-3.48\left(\mathrm{~m}, 2 \mathrm{H}, \mathrm{NCH}, \mathrm{CH}_{2} \mathrm{OH}\right), 3.45-3.37\left(\mathrm{~m}, 2 \mathrm{H}, \mathrm{NCH}_{2}\right), 3.26(\mathrm{dd}, J=17.1$, $12.7 \mathrm{~Hz}, 1 \mathrm{H}, 3-\mathrm{H}), 2.72(\mathrm{dd}, J=17.0 \mathrm{~Hz}, 2.7 \mathrm{~Hz}, 1 \mathrm{H}, 3-\mathrm{H}), 1.70-1.34\left(\mathrm{~m}, 5 \mathrm{H}, \mathrm{CH}_{2} \mathrm{CH}_{2} \mathrm{CH}_{2}\right), 1.31-1.18$ (m, 1H, $\mathrm{CH}_{2} \mathrm{CH}_{2} \mathrm{CH}_{2}$ ). ${ }^{13} \mathrm{C}-\mathrm{NMR}: \delta 197.25,167.12,166.26,163.44,163.05,148.42,146.93,131.45,118.26$, 114.60, 112.38, 103.07, 95.82, 94.82, 78.96, 66.42, 59.45, 56.11, 53.35, 42.65, 36.56, 25.92, 25.43, 21.22. HR-MS (ESI): Calcd. $\mathrm{C}_{24} \mathrm{H}_{27} \mathrm{NO}_{8},[\mathrm{M}+\mathrm{H}]^{+} m / z$ : 458.1819, found: 458.1827 .

7-O-(2-(4-Methylpiperazin-1-yl)-2-oxoethyl)hesperetin (6d)

White crystals, 56\% yield, m.p. $167.3-170.1{ }^{\circ} \mathrm{C} ;{ }^{1} \mathrm{H}-\mathrm{NMR}: \delta 12.08$ (s, 1H, 5-OH), $9.14\left(\mathrm{~s}, 1 \mathrm{H}, 3^{\prime}-\mathrm{OH}\right)$, 6.97-6.91 (m, 2H, 2'-H, 5'-H), 6.89 (dd, $\left.J=8.3,1.8 \mathrm{~Hz}, 1 \mathrm{H}, 6^{\prime}-\mathrm{H}\right), 6.10(\mathrm{~d}, J=2.2 \mathrm{~Hz}, 1 \mathrm{H}, 8-\mathrm{H}), 6.07$ (d, $J=2.2 \mathrm{~Hz}, 1 \mathrm{H}, 6-\mathrm{H}), 5.48(\mathrm{dd}, J=12.6,2.8 \mathrm{~Hz}, 1 \mathrm{H}, 2-\mathrm{H}), 4.92\left(\mathrm{~s}, 2 \mathrm{H}, \mathrm{ArOCH}_{2} \mathrm{C}=\mathrm{O}\right), 3.78\left(\mathrm{~s}, 3 \mathrm{H}, \mathrm{OCH}_{3}\right)$, $3.43\left(\mathrm{~m}, 2 \mathrm{H}, \mathrm{NCCH}_{2} \mathrm{NC}=\mathrm{O}\right), 3.39\left(\mathrm{~m}, 2 \mathrm{H}, \mathrm{NCCH}_{2} \mathrm{NC}=\mathrm{O}\right), 3.26(\mathrm{dd}, J=17.1,12.7 \mathrm{~Hz}, 1 \mathrm{H}, 3-\mathrm{H}), 2.73(\mathrm{dd}$, $J=17.1,3.0 \mathrm{~Hz}, 1 \mathrm{H}, 3-\mathrm{H}), 2.32\left(\mathrm{~m}, 2 \mathrm{H}, \mathrm{NCH}_{2} \mathrm{CNC}=\mathrm{O}\right), 2.26\left(\mathrm{~m}, 2 \mathrm{H}, \mathrm{NCH}_{2} \mathrm{CNC}=\mathrm{O}\right), 2.17\left(\mathrm{~s}, 3 \mathrm{H}, \mathrm{NCH}_{3}\right)$. 
${ }^{13}$ C-NMR: $\delta$ 197.30, 166.76, 165.37, 163.44, 163.08, 148.41, 146.93, 131.40, 118.23, 114.58, 112.36, 103.20, 95.83, 94.84, 78.96, 66.30, 56.10, 54.99, 54.67, 46.12, 44.28, 42.62, 41.61. HRMS (ESI): Calcd. $\mathrm{C}_{23} \mathrm{H}_{26} \mathrm{~N}_{2} \mathrm{O}_{7}$, $[\mathrm{M}+\mathrm{H}]^{+} m / z: 443.1823$, found: 443.1833 .

7-O-(2-(4-Ethylpiperazin-1-yl)-2-oxoethyl)hesperetin (6e)

White crystals, 58\% yield, m.p. $160.7-162.9^{\circ} \mathrm{C} ;{ }^{1} \mathrm{H}-\mathrm{NMR}: \delta 12.08$ (s, 1H, 5-OH), $9.14\left(\mathrm{~s}, 1 \mathrm{H}, 3^{\prime}-\mathrm{OH}\right)$, 6.96-6.91 (m, 2H, 2'-H, 5'-H), $6.89\left(\mathrm{~d}, J=8.2 \mathrm{~Hz}, 1 \mathrm{H}, 6^{\prime}-\mathrm{H}\right), 6.10(\mathrm{~d}, J=1.7 \mathrm{~Hz}, 1 \mathrm{H}, 8-\mathrm{H}), 6.07(\mathrm{~d}$, $J=1.9 \mathrm{~Hz}, 1 \mathrm{H}, 6-\mathrm{H}), 5.47(\mathrm{dd}, J=12.6,2.6 \mathrm{~Hz}, 1 \mathrm{H}, 2-\mathrm{H}), 4.92\left(\mathrm{~s}, 2 \mathrm{H}, \mathrm{ArOCH}_{2} \mathrm{C}=\mathrm{O}\right), 3.78\left(\mathrm{~s}, 3 \mathrm{H}, \mathrm{OCH}_{3}\right)$, $3.43\left(\mathrm{~m}, 2 \mathrm{H}, \mathrm{NCCH}_{2} \mathrm{NC}=\mathrm{O}\right), 3.39\left(\mathrm{~m}, 2 \mathrm{H}, \mathrm{NCCH}_{2} \mathrm{NC}=\mathrm{O}\right), 3.26(\mathrm{dd}, J=17.1,12.7 \mathrm{~Hz}, 1 \mathrm{H}, 3-\mathrm{H}), 2.73$ $(\mathrm{dd}, J=17.1,2.7 \mathrm{~Hz}, 1 \mathrm{H}, 3-\mathrm{H}), 2.42-2.26\left(\mathrm{~m}, 6 \mathrm{H}, \mathrm{N}\left(\mathrm{CH}_{2} \mathrm{C}\right)_{2} \mathrm{NC}=\mathrm{O}, \mathrm{NCH}_{2} \mathrm{C}\right), 0.99(\mathrm{t}, J=7.1 \mathrm{~Hz}, 3 \mathrm{H}$, $\left.\mathrm{NCCH}_{3}\right) .{ }^{13} \mathrm{C}-\mathrm{NMR}: \delta 197.30,166.77,165.32,163.44,163.08,148.41,146.93,131.40,118.23,114.58,112.36$, 103.20, 95.83, 94.85, 78.96, 66.31, 56.10, 52.85, 52.40, 51.97, 44.41, 42.63, 41.73, 12.33. HRMS (ESI): Calcd. $\mathrm{C}_{24} \mathrm{H}_{28} \mathrm{~N}_{2} \mathrm{O}_{7},[\mathrm{M}+\mathrm{H}]^{+} m / z: 457.1979$, found: 457.1985 .

7-O-(2-Morpholino-2-oxoethyl)hesperetin (6f)

White powder, 73\% yield, m.p. 188.7-189. ${ }^{\circ} \mathrm{C} ;{ }^{1} \mathrm{H}-\mathrm{NMR}: \delta 12.08$ (s, 1H, 5-OH), $9.13\left(\mathrm{~s}, 1 \mathrm{H}, 3{ }^{\prime}-\mathrm{OH}\right)$, 6.96-6.92 (m, 2H, 2'-H, 5'-H), $\left.6.89\left(\mathrm{dd}, J=8.4,1.7 \mathrm{~Hz}, 1 \mathrm{H}, 6^{\prime}-\mathrm{H}\right), 6.11(\mathrm{~d}, J=2.2 \mathrm{~Hz}, 1 \mathrm{H}, 8-\mathrm{H})\right), 6.09$ $(\mathrm{d}, J=2.2 \mathrm{~Hz}, 1 \mathrm{H}, 6-\mathrm{H})), 5.48(\mathrm{dd}, J=12.6,2.7 \mathrm{~Hz}, 1 \mathrm{H}, 2-\mathrm{H})), 4.94\left(\mathrm{~s}, 2 \mathrm{H}, \mathrm{ArOCH}_{2} \mathrm{C}=\mathrm{O}\right), 3.78(\mathrm{~s}, 3 \mathrm{H}$, $\left.\mathrm{OCH}_{3}\right), 3.63-3.52\left(\mathrm{~m}, 4 \mathrm{H}, \mathrm{O}\left(\mathrm{CH}_{2} \mathrm{C}\right)_{2} \mathrm{~N}\right), 3.42\left(\mathrm{~m}, 4 \mathrm{H}, \mathrm{O}\left(\mathrm{CCH}_{2}\right)_{2} \mathrm{~N}\right), 3.27(\mathrm{dd}, J=17.1,12.7 \mathrm{~Hz}, 1 \mathrm{H}, 3-\mathrm{H})$, $2.73(\mathrm{dd}, J=17.1,2.9 \mathrm{~Hz}, 1 \mathrm{H}, 3-\mathrm{H}) .{ }^{13} \mathrm{C}-\mathrm{NMR}: \delta 197.32,166.75,165.65,163.44,163.10,148.42,146.92$, 131.40, 118.25, 114.59, 112.36, 103.22, 95.86, 94.85, 78.98, 66.49, 66.37, 66.21, 56.10, 44.92, 42.62, 42.01. HR-MS (ESI): Calcd. $\mathrm{C}_{22} \mathrm{H}_{23} \mathrm{NO}_{8},[\mathrm{M}+\mathrm{H}]^{+} \mathrm{m} / z$ : 430.1506, found: 430.1511 .

7-O-(2-((2-Hydroxyethyl)amino)-2-oxoethyl)hesperetin (7a)

White crystals, $40 \%$ yield, m.p. $183.8-185.7^{\circ} \mathrm{C} ;{ }^{1} \mathrm{H}-\mathrm{NMR}: \delta 12.08$ (s, 1H, 5-OH), 9.13 (s, 1H, 3'-OH), $8.09(\mathrm{t}, J=5.6 \mathrm{~Hz}, 1 \mathrm{H}, \mathrm{NH}), 6.95-6.93\left(\mathrm{~m}, 2 \mathrm{H}, 2^{\prime}-\mathrm{H}, 5^{\prime}-\mathrm{H}\right), 6.89\left(\mathrm{dd}, J=8.4,1.8 \mathrm{~Hz}, 1 \mathrm{H}, 6^{\prime}-\mathrm{H}\right), 6.12(\mathrm{~d}$, $J=2.2 \mathrm{~Hz}, 1 \mathrm{H}, 8-\mathrm{H}), 6.10(\mathrm{~d}, J=2.2 \mathrm{~Hz}, 1 \mathrm{H}, 6-\mathrm{H}), 5.49(\mathrm{dd}, J=12.4,2.9 \mathrm{~Hz}, 1 \mathrm{H}, 2-\mathrm{H}), 4.74(\mathrm{t}, J=5.5 \mathrm{~Hz}$, $1 \mathrm{H}, \mathrm{OH}), 4.55\left(\mathrm{~s}, 2 \mathrm{H}, \mathrm{ArOCH}_{2} \mathrm{C}=\mathrm{O}\right), 3.78\left(\mathrm{~s}, 3 \mathrm{H}, \mathrm{OCH}_{3}\right), 3.43\left(\mathrm{q}, J=5.9 \mathrm{~Hz}, 2 \mathrm{H}, \mathrm{NCCH}_{2} \mathrm{O}\right), 3.27(\mathrm{dd}$, $J=17.2,12.5 \mathrm{~Hz}, 1 \mathrm{H}, 3-\mathrm{H}), 3.20\left(\mathrm{q}, J=6.0 \mathrm{~Hz}, 2 \mathrm{H}, \mathrm{NCH}_{2} \mathrm{CO}\right), 2.76(\mathrm{dd}, J=17.1,3.0 \mathrm{~Hz}, 1 \mathrm{H}, 3-\mathrm{H})$. ${ }^{13}$ C-NMR: $\delta$ 197.38, 167.29, 166.16, 163.49, 163.12, 148.41, 146.93, 131.37, 118.21, 114.56, 112.40, 103.42, 95.82, 94.87, 78.93, 67.40, 60.06, 56.11, 42.58, 41.71. HR-MS (ESI): Calcd. $\mathrm{C}_{20} \mathrm{H}_{21} \mathrm{NO}_{8},[\mathrm{M}+\mathrm{H}]^{+} \mathrm{m} / z$ : 404.1360, found: 404.1369 .

7-O-(2-((2-(Dimethylamino)ethyl)amino)-2-oxoethyl)hesperetin (7b)

White crystals, 52\% yield, m.p. $137.1-139.4{ }^{\circ} \mathrm{C} ;{ }^{1} \mathrm{H}-\mathrm{NMR}: \delta 12.08$ (s, 1H, 5-OH), 9.15 (s, 1H, 3'-OH), $8.04(\mathrm{t}, J=5.6 \mathrm{~Hz}, 1 \mathrm{H}, \mathrm{NH}), 6.95-6.93\left(\mathrm{~m}, 2 \mathrm{H}, 2^{\prime}-\mathrm{H}, 5^{\prime}-\mathrm{H}\right), 6.88\left(\mathrm{dd}, J=8.4,1.7 \mathrm{~Hz}, 1 \mathrm{H}, 6^{\prime}-\mathrm{H}\right), 6.11$ $(\mathrm{d}, J=2.2 \mathrm{~Hz}, 1 \mathrm{H}, 8-\mathrm{H}), 6.09(\mathrm{~d}, J=2.2 \mathrm{~Hz}, 1 \mathrm{H}, 6-\mathrm{H}), 5.49(\mathrm{dd}, J=12.4,2.8 \mathrm{~Hz}, 1 \mathrm{H}, 2-\mathrm{H}), 4.55(\mathrm{~s}, 2 \mathrm{H}$, $\left.\mathrm{ArOCH}_{2} \mathrm{C}=\mathrm{O}\right), 3.78\left(\mathrm{~s}, 3 \mathrm{H}, \mathrm{OCH}_{3}\right), 3.32-3.16\left(\mathrm{~m}, 3 \mathrm{H}, 3-\mathrm{H}, \mathrm{NCCH}_{2} \mathrm{NC}=\mathrm{O}\right), 2.76(\mathrm{dd}, J=17.1,3.0 \mathrm{~Hz}, 1 \mathrm{H}$, 3-H), $2.30\left(\mathrm{t}, J=6.6 \mathrm{~Hz}, 2 \mathrm{H}, \mathrm{NCH}_{2} \mathrm{CNC}=\mathrm{O}\right), 2.13\left(\mathrm{~s}, 6 \mathrm{H},\left(\mathrm{CH}_{3}\right)_{2} \mathrm{~N}\right) .{ }^{13} \mathrm{C}-\mathrm{NMR}: \delta 197.25,167.12,166.27$, 163.44, 163.05, 148.42, 146.93, 131.45, 118.26, 114.60, 112.38, 103.07, 95.82, 94.80, 78.96, 66.42, 60.24, 59.45, 56.11, 53.35, 42.65, 36.56. HRMS (ESI): Calcd. $\mathrm{C}_{22} \mathrm{H}_{26} \mathrm{~N}_{2} \mathrm{O}_{7},[\mathrm{M}+\mathrm{H}]^{+} m / z: 431.1823$, found: 431.1830.

7-O-(2-((2-Mmorpholinoethyl)amino)-2-oxoethyl) hesperetin (7c)

White crystals, $54 \%$ yield, m.p. $160.7-162.9^{\circ} \mathrm{C} ;{ }^{1} \mathrm{H}-\mathrm{NMR}: \delta 12.08(\mathrm{~s}, 1 \mathrm{H}, 5-\mathrm{OH}), 9.13\left(\mathrm{~s}, 1 \mathrm{H}, 3^{\prime}-\mathrm{OH}\right)$, $8.02(\mathrm{t}, J=5.6 \mathrm{~Hz}, 1 \mathrm{H}, \mathrm{NH}), 6.95-6.93\left(\mathrm{~m}, 2 \mathrm{H}, 2^{\prime}-\mathrm{H}, 5^{\prime}-\mathrm{H}\right), 6.88\left(\mathrm{dd}, J=8.3,1.8 \mathrm{~Hz}, 1 \mathrm{H}, 6^{\prime}-\mathrm{H}\right), 6.11$ $(\mathrm{d}, J=2.1 \mathrm{~Hz}, 1 \mathrm{H}, 8-\mathrm{H}), 6.10(\mathrm{~d}, J=2.1 \mathrm{~Hz}, 1 \mathrm{H}, 6-\mathrm{H}), 5.48(\mathrm{dd}, J=12.4,2.8 \mathrm{~Hz}, 1 \mathrm{H}, 2-\mathrm{H}), 4.56(\mathrm{~s}, 2 \mathrm{H}$, $\left.\mathrm{ArOCH}_{2} \mathrm{C}=\mathrm{O}\right), 3.78\left(\mathrm{~s}, 3 \mathrm{H}, \mathrm{OCH}_{3}\right), 3.58-3.46\left(\mathrm{~m}, 4 \mathrm{H},\left(\mathrm{OCH}_{2} \mathrm{CN}\right)_{2}\right), 3.33-3.18\left(\mathrm{~m}, 3 \mathrm{H}, \mathrm{NCCH}_{2} \mathrm{NC}=\mathrm{O}\right.$, $3-\mathrm{H}), 2.76(\mathrm{dd}, J=17.1,3.0 \mathrm{~Hz}, 1 \mathrm{H}, 3-\mathrm{H}), 2.37-2.34\left(\mathrm{~m}, J=6.5 \mathrm{~Hz}, 6 \mathrm{H},\left(\mathrm{OCCH}_{2} \mathrm{~N}\right)_{2}, \mathrm{NCH}_{2} \mathrm{CNC}=\mathrm{O}\right)$. ${ }^{13}$ C-NMR: $\delta 197.39,167.16,166.13,163.50,163.14,148.42,146.93,131.35,118.20,114.56,112.37,103.43$, 
95.86, 94.87, 78.98, 67.45, 66.61, 66.61, 57.62, 56.10, 53.65, 42.60, 35.98. HRMS (ESI): Calcd. $\mathrm{C}_{24} \mathrm{H}_{28} \mathrm{~N}_{2} \mathrm{O}_{8}$ ， $[\mathrm{M}+\mathrm{H}]^{+} m / z: 473.1928$, found: 473.1932 .

HRMS, ${ }^{1} \mathrm{H}-\mathrm{NMR}$ and ${ }^{13} \mathrm{C}-\mathrm{NMR}$ of the compounds are available in Supplementary Materials.

\subsection{Biological Assays}

\subsubsection{Cell Culture}

The RAW264.7 cell line was purchased from Cell Bank of Chinese Academy of Sciences (Shanghai, China). The cells were cultured in DMEM (Hyclone, Logan, UT, USA), supplemented with $10 \%$ fetal bovine serum (Biological industries) and antibiotics (100 U/mL penicillin A and $100 \mathrm{U} / \mathrm{mL}$ streptomycin), and maintained at $37^{\circ} \mathrm{C}$ in a humidified atmosphere containing $5 \% \mathrm{CO}_{2}$ [31].

\subsubsection{Determination of Cell Viability}

Cytotoxicity and cell viability was evaluated by a MTT (Sigma, Shanghai, China) assay using a method similar to the one described above [25]. Cells were inoculated at a density of $7.0 \times 10^{3}$ cells/well into 96-well plate and cultured at $37^{\circ} \mathrm{C}$ for $12 \mathrm{~h}$. Culture cells treated with the same one-thousandth of the DMSO solvent as the vehicle (control) and $40 \mu \mathrm{M}$ compounds for $24 \mathrm{~h}$. After that, MTT dissolved in phosphate buffered saline (PBS) and was added to the culture medium to reach a final concentration of $0.5 \mathrm{mg} / \mathrm{mL}$ and incubated for another $4 \mathrm{~h}$. The media was removed and $200 \mu \mathrm{L}$ of DMSO was added and incubated for $30 \mathrm{~min}$. Finally, the cell viability (\%) was calculated based on the absorbance measured at the wavelength of $490 \mathrm{~nm}$ and measured using a microplate reader (Synergy HTX, Biotek, Winowski, VT, USA). The cell viability were calculated by GraphPad Prism 6 (GraphPad, San Diego, CA, USA).

\subsubsection{Assessment of Nitric Oxide (NO)}

Nitrite levels were determined using the Griess method for NO has a short half-life and is oxidized to stable nitrite. RAW 264.7 cells were plated at a density of $2 \times 10^{5}$ per well in a 24-well culture plate and incubated in a $37{ }^{\circ} \mathrm{C}$ humidified incubator $\left(5 \% \mathrm{CO}_{2}\right)$ [32]. After overnight Cultured, discarded the supernatant, added pre-configured compounds of different concentrations to the 24-well plate, and added the same one-thousandth of the DMSO solvent as the control to the experimental group for $1 \mathrm{~h}$. Then LPS was added to experimental and model groups at a concentration of $1 \mathrm{mg} / \mathrm{mL}$ for $24 \mathrm{~h}$ compared to vehicle control. Following treatment, media was collected and centrifuged at $2000 \mathrm{rpm}$ for $5 \mathrm{~min}$ to remove cellular debris. The medium from treated cells was removed and placed into a 96-well plate ( $50 \mu \mathrm{L}$ per well) and was measured in culture supernatant using Griess reagent at $540 \mathrm{~nm}$. The $\mathrm{IC}_{50}$ values of compounds were calculated by SPSS23.

\subsubsection{Measurement of Cytokines}

RAW264.7 cells $\left(2 \times 10^{5}\right.$ cells/well) were cultured in 24 -well plate and pretreated with $10 \mu \mathrm{M}$ of compounds for $1 \mathrm{~h}$. And then stimulated with LPS, $1 \mathrm{mg} / \mathrm{mL}$, for $24 \mathrm{~h}$. The cell culture supernatant were collected and the levels of TNF- $\alpha$, IL- 6 and IL- $1 \beta$ were determined using the ELISA kit (Elabscience, Wuhan, China). The optical density (OD) was measured at $540 \mathrm{~nm}$ [33]. The results were analyzed using Origin Pro 8 (OriginLab, Northampton, MA, USA).

\subsubsection{Western Blotting Analysis}

After the treatment with LPS $(1 \mathrm{mg} / \mathrm{mL})$ in the presence different concentration gradient or absence of compounds, removed culture supernatants, and cells were collected and lysed with RIPA lysis buffer (Beyotime, Shanghai, China) and phosphatase inhibitors (Beibokit, Bestbio, Shanghai, China). After centrifugation $\left(4^{\circ} \mathrm{C}, 30 \mathrm{~min}, 12,000 \mathrm{rpm}\right.$, Beckman Coulter, Inc., Fullerton, CA, USA), the total protein concentration was determined using BCA Protein Assay Kit (Beyotime, Shanghai, China). Lysates containing $30 \mathrm{mg}$ of total proteins were fractionated on SDS polyacrylamide gel and transferred to a 
polyvinylidene difluoride membranes (PVDF) (Merck Millipore, Tullagreen Carrigtwohill, Ireland). Membranes were blocked with 5\% skim milk or 3\% BSA (Albumin Bovine V, Sigma) in TBST and incubated at $4{ }^{\circ} \mathrm{C}$ overnight with their respective primary antibody: $\beta$-actin (1:1000 dilution; Abcam, Cambridge, MA, USA), iNOS (1:1000 dilution; Abcam, Cambridge, MA, USA), COX-2 (1:1000 dilution; CST, Danvers, MA, USA ), NF-KB (1:1000 dilution; CST, Danvers, MA, USA). After washing three times with TBST, membranes were incubated with secondary antibody for $1 \mathrm{~h}$ in room temperature on the shaker. Protein bands were visualized by the ultra-sensitive enhanced chemiluminescent (ECL) substrate (ECL-plus, Thermo Scientific, Rockford, IL, USA), after washing three times with TBST [34].

\section{Statistical Analysis}

All experiments were repeated at least three times. Data are presented as the means \pm standard deviation (SD) for the indicated number of independently performed experiments. The significance of differences between drug-treated groups compared to vehicle was determined by one way ANOVA using SPSS 23 (IBM, Chicago, IL, USA). The difference was considered statistically significant when $p$ $\left(^{*}\right)<0.05, p\left(^{* *}\right)<0.01, p\left({ }^{* *}\right)<0.001$ or no significance (ns).

\section{Conclusions}

In conclusion, based on their structural characteristics, a series of 7-O-amide hesperetin derivatives were designed and synthesized as potential anti-inflammatory agents. In vitro bioassays showed that title compounds could be alleviated the increase of NO release in LPS-induced RAW264.7 cells. The 7-O-amide side chains were buried in a medium-sized hydrophobic cavity of the bound receptor, while with a suitably extended length of the amide side chain the inhibitory activities were increased. Compounds $\mathbf{4} \mathbf{d}$ and $\mathbf{4 k}$ exhibited more potent inhibitory activity towards NO, IL-6, IL-1 $\beta$ and TNF- $\alpha$ than celecoxib and indomethacin. Further, western blotting showed that compound $4 \mathbf{d}$ significantly decreased the expression levels of iNOS and COX-2, as well as activation of NF-KB in LPS-stimulated RAW264.7 cells. Taken together, compound $4 \mathbf{d}$ exerted its anti-inflammatory activity through inhibition of NO generation as a result of inhibiting NF- $\mathrm{KB}$ signalling pathways. These results could be very useful for a SAR study in the future, when we will proceed with modification of the hesperetin structure at the $3^{\prime}-\mathrm{OH}, 5-\mathrm{OH}$ and 4-carbonyl positions.

\section{Patents}

A patent application resulting from the work reported in this manuscript has been submitted to the National Intellectual Property Administration (PRC). The patent application number is CN201910754986.4.

Supplementary Materials: The following are available online, Figure S1-S3: HRMS, ${ }^{1} \mathrm{H}-\mathrm{NMR}$ : and ${ }^{13} \mathrm{C}-\mathrm{NMR}$ : spectra for the compound 1-3, Figure S4-S26: HRMS, ${ }^{1} \mathrm{H}-\mathrm{NMR}$ : and ${ }^{13} \mathrm{C}-\mathrm{NMR}$ : spectra for the target compound 1-3, 4a-1, 5a-b, 6a-f, 7a-c.

Author Contributions: Conceptualization, J.L., Y.Z. (Yilong Zhang) and Y.Z. (Yan Zheng); Experiments, Y.Z. (Yilong Zhang), Y.Z. (Yan Zheng), W.S. and Y.G.; Investigation, Y.Z. (Yilong Zhang) and Y.Z. (Yan Zheng); Project administration, J.L. and C.H.; Writing-original draft preparation, Y.Z. (Yilong Zhang) and Y.Z. (Yan Zheng); Writing-review and editing, Z.L., T.X., C.H. and J.L.; Funding acquisition, J.L. and C.H.

Funding: Financial support by the National Natural Science Foundation of China (No. 81770609) and Higher Education Natural Science Foundation of Anhui Province (KJ2019A0233) is gratefully acknowledged.

Conflicts of Interest: The authors declare no conflict of interest.

\section{References}

1. Moser, B.; Willimann, K. Chemokines: Role in inflammation and immune surveillance. Ann. Rheum. Dis. 2004, 63 (Suppl. 2), ii84-ii89. [CrossRef] 
2. Philkhana, S.C.; Verma, A.K.; Jachak, G.R.; Hazra, B.; Basu, A.; Reddy, D.S. Identification of new anti-inflammatory agents based on nitrosporeusine natural products of marine origin. Eur. J. Med. Chem. 2017, 135, 89-109. [CrossRef] [PubMed]

3. Soehnlein, O.; Steffens, S.; Hidalgo, A.; Weber, C. Neutrophils as protagonists and targets in chronic inflammation. Nat. Rev. Immunol. 2017, 17, 248-261. [CrossRef] [PubMed]

4. Chen, R.; Li, L.; Shen, C.; Huang, C.; Ma, T.; Meng, X.; Qian, Z.; Li, Y.; Li, J. Intestinal transport of HDND-7, a novel hesperetin derivative, in in vitro MDCK cell and in situ single-pass intestinal perfusion models. Xenobiotica 2017, 47, 719-730. [CrossRef] [PubMed]

5. Mulvihill, E.E.; Burke, A.C.; Huff, M.W. Citrus Flavonoids as Regulators of Lipoprotein Metabolism and Atherosclerosis. Annu. Rev. Nutr. 2016, 36, 275-299. [CrossRef]

6. Jo, S.H.; Kim, M.E.; Cho, J.H.; Lee, Y.; Lee, J.; Park, Y.D.; Lee, J.S. Hesperetin inhibits neuroinflammation on microglia by suppressing inflammatory cytokines and MAPK pathways. Arch. Pharm. Res. 2019. [CrossRef]

7. Ma, Y.; He, Y.; Yin, T.; Chen, H.; Gao, S.; Hu, M. Metabolism of Phenolic Compounds in LPS-stimulated Raw264.7 Cells Can Impact Their Anti-inflammatory efficacy: Indication of Hesperetin. J. Agric. Food Chem. 2018, 66, 6042-6052. [CrossRef]

8. Jung, K.Y.; Park, J.; Han, Y.S.; Lee, Y.H.; Shin, S.Y.; Lim, Y. Synthesis and biological evaluation of hesperetin derivatives as agents inducing apoptosis. Bioorg. Med. Chem. 2017, 25, 397-407. [CrossRef]

9. Hwang, S.L.; Yen, G.C. Effect of hesperetin against oxidative stress via ER- and TrkA-mediated actions in PC12 cells. J. Agric. Food. Chem. 2011, 59, 5779-5785. [CrossRef]

10. Paredes, A.; Alzuru, M.; Mendez, J.; Rodriguez-Ortega, M. Anti-Sindbis activity of flavanones hesperetin and naringenin. Biol. Pharm. Bull. 2003, 26, 108-109. [CrossRef]

11. Ikram, M.; Muhammad, T.; Rehman, S.U.; Khan, A.; Jo, M.G.; Ali, T.; Kim, M.O. Hesperetin Confers Neuroprotection by Regulating Nrf2/TLR4/NF-kappaB Signaling in an Abeta Mouse Model. Mol. Neurobiol. 2019, 56, 6293-6309. [CrossRef] [PubMed]

12. Shimouchi, A.; Yokota, H.; Ono, S.; Matsumoto, C.; Tamai, T.; Takumi, H.; Narayanan, S.P.; Kimura, S.; Kobayashi, H.; Caldwell, R.B.; et al. Neuroprotective effect of water-dispersible hesperetin in retinal ischemia reperfusion injury. Jpn. J. Ophthalmol. 2016, 60, 51-61. [CrossRef] [PubMed]

13. Rainey-Smith, S.; Schroetke, L.W.; Bahia, P.; Fahmi, A.; Skilton, R.; Spencer, J.P.; Rice-Evans, C.; Rattray, M.; Williams, R.J. Neuroprotective effects of hesperetin in mouse primary neurones are independent of CREB activation. Neurosci. Lett. 2008, 438, 29-33. [CrossRef] [PubMed]

14. Maiti, K.; Mukherjee, K.; Murugan, V.; Saha, B.P.; Mukherjee, P.K. Exploring the effect of Hesperetin-HSPC complex-a novel drug delivery system on the in vitro release, therapeutic efficacy and pharmacokinetics. Aaps. Pharmscitech. 2009, 10, 943-950. [CrossRef] [PubMed]

15. Kanaze, F.I.; Bounartzi, M.I.; Georgarakis, M.; Niopas, I. Pharmacokinetics of the citrus flavanone aglycones hesperetin and naringenin after single oral administration in human subjects. Eur. J. Clin. Nutr. 2007, 61, 472-477. [CrossRef] [PubMed]

16. Ding, H.W.; Huang, A.L.; Zhang, Y.L.; Li, B.; Huang, C.; Ma, T.T.; Meng, X.M.; Li, J. Design, synthesis and biological evaluation of hesperetin derivatives as potent anti-inflammatory agent. Fitoterapia 2017, 121, 212-222. [CrossRef] [PubMed]

17. Meng, H.W.; You, H.M.; Yang, Y.; Zhang, Y.L.; Meng, X.M.; Ma, T.T.; Huang, C.; Li, J. 4-Methylcoumarin-[5,6-g]-hesperetin attenuates inflammatory responses in alcoholic hepatitis through PPAR-gamma activation. Toxicology 2019, 421, 9-21. [CrossRef]

18. Chen, X.; Ding, H.W.; Li, H.D.; Huang, H.M.; Li, X.F.; Yang, Y.; Zhang, Y.L.; Pan, X.Y.; Huang, C.; Meng, X.M.; et al. Hesperetin derivative-14 alleviates inflammation by activating PPAR-gamma in mice with CCl4-induced acute liver injury and LPS-treated RAW264.7 cells. Toxicol. Lett. 2017, 274, 51-63. [CrossRef]

19. Shen, C.; Qian, Z.; Chen, R.; Meng, X.; Hu, T.; Chen, Z.; Li, Y.; Huang, C.; Hu, C.; Li, J. Single Dose Oral and Intravenous Pharmacokinetics and Tissue Distribution of a Novel Hesperetin Derivative MTBH in Rats. Eur. J. Drug Metab. Pharm. 2016, 41, 675-688. [CrossRef]

20. Shen, C.; Chen, R.; Qian, Z.; Huang, C.; Meng, X.; Ma, T.; Chen, Z.; Huang, X.; Li, L.; Zang, H.; et al. A HPLC-MS/MS method for the quantitation of free, conjugated, and total HDND-7, a novel hesperetin derivative, in rat plasma and tissues: Application to the pharmacokinetic and tissue distribution study. $J$. Pharm. Biomed. Anal. 2016, 118, 149-160. [CrossRef] 
21. Li, B.; Huang, A.L.; Zhang, Y.L.; Li, Z.; Ding, H.W.; Huang, C.; Meng, X.M.; Li, J. Design, Synthesis and Evaluation of Hesperetin Derivatives as Potential Multifunctional Anti-Alzheimer Agents. Molecules 2017, 22, 1067. [CrossRef] [PubMed]

22. Huang, A.L.; Zhang, Y.L.; Ding, H.W.; Li, B.; Huang, C.; Meng, X.M.; Li, J. Design, synthesis and investigation of potential anti-inflammatory activity of $\mathrm{O}-\mathrm{alkyl}$ and $\mathrm{O}-$ benzyl hesperetin derivatives. Int. Immunopharmacol. 2018, 61, 82-91. [CrossRef] [PubMed]

23. Correia-da-Silva, M.; Sousa, E.; Duarte, B.; Marques, F.; Carvalho, F.; Cunha-Ribeiro, L.M.; Pinto, M.M. Flavonoids with an oligopolysulfated moiety: A new class of anticoagulant agents. J. Med. Chem. 2011, 54, 95-106. [CrossRef] [PubMed]

24. Zhang, H.B.; Shen, Q.K.; Wang, H.; Jin, C.; Jin, C.M.; Quan, Z.S. Synthesis and evaluation of novel arctigenin derivatives as potential anti-Toxoplasma gondii agents. Eur. J. Med. Chem. 2018, 158, 414-427. [CrossRef] [PubMed]

25. Li, B.; Cai, S.; Yang, Y.A.; Chen, S.C.; Chen, R.; Shi, J.B.; Liu, X.H.; Tang, W.J. Novel unsaturated glycyrrhetic acids derivatives: Design, synthesis and anti-inflammatory activity. Eur. J. Med. Chem. 2017, 139, 337-348. [CrossRef] [PubMed]

26. Huang, Y.; Zhang, B.; Li, J.; Liu, H.; Zhang, Y.; Yang, Z.; Liu, W. Design, synthesis, biological evaluation and docking study of novel indole-2-amide as anti-inflammatory agents with dual inhibition of COX and 5-LOX. Eur. J. Med. Chem. 2019, 180, 41-50. [CrossRef]

27. Tang, M.L.; Zhong, C.; Liu, Z.Y.; Peng, P.; Liu, X.H.; Sun, X. Discovery of novel sesquistilbene indanone analogues as potent anti-inflammatory agents. Eur. J. Med. Chem. 2016, 113, 63-74. [CrossRef] [PubMed]

28. Muhammad, T.; Ikram, M.; Ullah, R.; Rehman, S.U.; Kim, M.O. Hesperetin, a Citrus Flavonoid, Attenuates LPS-Induced Neuroinflammation, Apoptosis and Memory Impairments by Modulating TLR4/NF-kappaB Signaling. Nutrients 2019, 11, 648. [CrossRef]

29. Lipinski, C.A.; Lombardo, F.; Dominy, B.W.; Feeney, P.J. Experimental and computational approaches to estimate solubility and permeability in drug discovery and development settings. Adv Drug Deliv Rev 1997, 23, 3-25. [CrossRef]

30. Priyathilaka, T.T.; Bathige, S.; Lee, S.; Lee, J. Molecular identification and functional analysis of two variants of myeloid differentiation factor 88 (MyD88) from disk abalone (Haliotis discus discus). Dev. Comp. Immunol. 2018, 79, 113-127. [CrossRef]

31. Ju, Z.; Su, M.; Hong, J.; La Kim, E.; Moon, H.R.; Chung, H.Y.; Kim, S.; Jung, J.H. Design of balanced COX inhibitors based on anti-inflammatory and/or COX-2 inhibitory ascidian metabolites. Eur. J. Med. Chem. 2019, 180, 86-98. [CrossRef] [PubMed]

32. Chen, L.Z.; Sun, W.W.; Bo, L.; Wang, J.Q.; Xiu, C.; Tang, W.J.; Shi, J.B.; Zhou, H.P.; Liu, X.H. New arylpyrazoline-coumarins: Synthesis and anti-inflammatory activity. Eur. J. Med. Chem. 2017, 138, 170-181. [CrossRef] [PubMed]

33. Wang, B.; Li, L.; Jin, P.; Li, M.; Li, J. Hesperetin protects against inflammatory response and cardiac fibrosis in postmyocardial infarction mice by inhibiting nuclear factor kappaB signaling pathway. Exp. Ther. Med. 2017, 14, 2255-2260. [CrossRef] [PubMed]

34. Ren, Y.; Ma, Y.; Zhang, Z.; Qiu, L.; Zhai, H.; Gu, R.; Xie, Y. Total Alkaloids from Bamboo Shoots and Bamboo Shoot Shells of Pleioblastus amarus (Keng) Keng f. and Their Anti-Inflammatory Activities. Molecules 2019, 24, 2699. [CrossRef] [PubMed]

Sample Availability: Samples of the compounds 1-3, $\mathbf{4 a - 1}, \mathbf{5 a}-\mathbf{b}, \mathbf{6 a}-\mathbf{f}, \mathbf{7 a - c}$ are available from the authors. 